UNITED STATES DEPARTMENT OF THE INTERIOR

Harold L. Ickes, Secretary

GEOLOGICAL SURVEY

W. C. Mendenhall, Director

Bulletin 895-B

\title{
GEOPHYSICAL ABSTRACTS 89
}

\section{APRIL-JUNE 1937}

COMPILED BY

W. AYVAZOGLOU

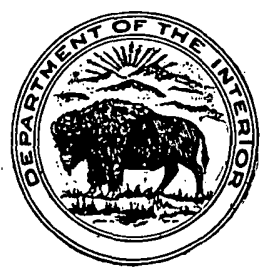

UNITED STATES

GOVERNMENT PRINTING OFFICE

WASHINGTON : 1938 


\section{CONTENTS}

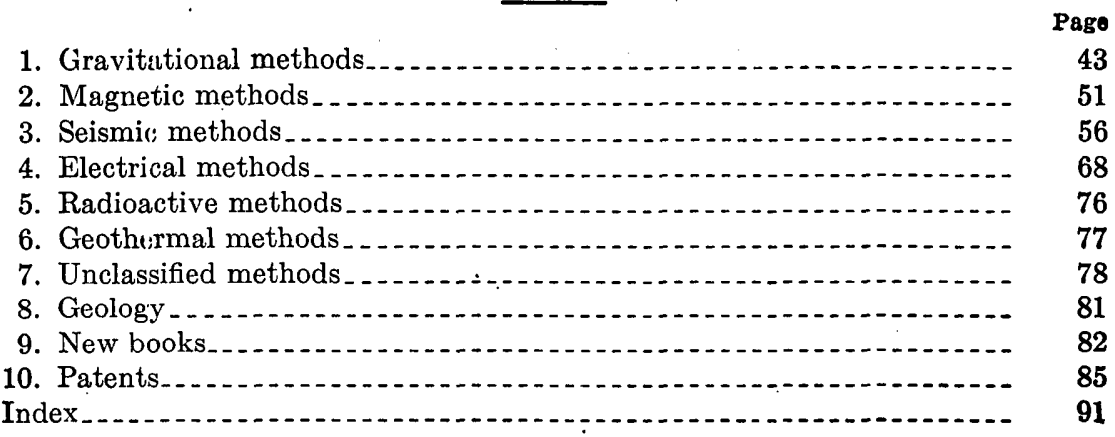

NoTE.-Geophysical Abstracts 1-86 were issued in mimeographed form by the Bureau of Mines. No. 87, containing abstracts for the period July to December 1936 and an index to abstracts 81-87, January to December 1936, was published as Geological Survey Bulletin 887. No. 88, containing abstracts for January to March 1937, was published as Bulletin 895-A. 


\title{
GEOPHYSICAL ABSTRACTS 89, APRIL-JUNE 1937
}

\author{
Compiled by W. Arvazogrou
}

\section{GRAVITATIONAL METHODS}

3657. Evsejev, s. V., Computation of corrections of topographical effects, socalled "curvatures" used in torsion-balance observations [in Russian] ; Acad. sci. U. R. S. S., Inst. séismol., Pub. 50, 13 pp., 1935.

Formulas are derived for the so-called "curvatures" by which the gravitational field produced by the surface masses is characterized:

$$
\begin{gathered}
2 U_{x y}=2 \frac{\partial^{2} V}{\partial x \partial y} \\
U_{\Delta}=\frac{\partial^{2} V}{\partial x^{2}}-\frac{\partial^{2} V}{\partial y^{2}}
\end{gathered}
$$

3658. Glennie, E. A., The depth of the Gangetic and Cuddapah downwarps in India: Beitr. angew. Geophysik, vol. 6, no. 3, pp. 311-318, Leipzig, 1937.

Professor Ansel's paper "Gravity anomalies with regard to the form of disturbance of connecting layers in the earth's crust" (Geophys' Abstracts 88, no. 3525) is discussed, and it is concluded that the hypothesis first formulated by the writer in 1931 that warpings of the crustal layers extend down to. a depth of about 30 kilometers is justified by the facts. The empirical method developed to apply this hypothesis is shown to give results which are sufficiently correct if the general paucity of data is taken into account. Densities in the Cuddapah basin and in the Gangetic trough are discussed and their effect on gravity anomalies considered.-Author's abstract.

3659. Gunn, R., Origin of continents and their motions : Franklin Inst. Jour., vol. 222, no. 4, pp. 475-492, 1936.

Geophysical data emphasize the unusual nature of the Pacific basin with its encircling mountain chains and suggest that the sub-Pacific layers of appreciable strength are 1 to 2 percent denser than elsewhere. It is shown that, as a result of this asymmetry and the isostatic adjustment of the continents, the mass per unit area of the earth's outer shell in Pacific regions is about 0.03 percent greater than in the continents. This mass asymmetry produces geologically important tangential forces on the continents of gravitational origin, which frequently compress their boundaries, playing an important part in mountain building and may produce continental motions. The force of North America urging it to south and west is approximately $10^{25}$ dynes and is adequate or nearly adequate to crush or produce overthrusting in the resisting Pacific basin, permitting continental motion with a velocity of the order of an inch per year. The theory of the 
earth's origin is particularly adapted to describe the origin of the continents and the observed asymmetry of their distribution.- $R$. S. R., Sci. Abstract, vol. 39, no. 467, 1936.

3660. Holweck, F., Holweck-Lejay gravimeter : Bull. géodesique, no. 46, pp. 295303, Paris, April-June 1935.

Instruments of the gravimeter type are designed to accelerate the determination of the force of gravity $g$ at a large number of stations within an area of several thousand square miles, with the object of amplifying geodetic and geophysical data obtained at relatively scattered positions by means of the standard invariable pendulum. The Holweck-Lejay gravimeter employs an inverted elastic pendulum supported by a lamellar spring, in which the effect of $g$ as a restoring force is very nearly balanced by the elastic torque of the supporting strip. In this way the sensitivity of the pendulum is very greatly magnified, and a long period of oscillation is obtained with a relatively light and portable apparatus. To insure reasonable accuracy, careful protection from temperature effects is essential. The supporting strip is made of elinvar, and the pendulum arm of quartz supports a mass of only a few grams. The whole system is mounted within a vacuum chamber. A measurement of $g$ at one station occupies about 1 or 2 hours, and the apparatus can be rapidly transported within a motor truck, supported by elastic suspensions. On test, one observer measured $g$ at 153 stations in China, covering an area of $500,000 \mathrm{~km}^{2}$ in a single year. Comparison with standard pendulum observations showed an average error of 1.1 milligal.-E. L.-J., Sci. Abstracts, vol. 39, no. 46\%, 1936.

8661. Horsfield, W., and Bullard, E. C., Gravity measurements in Tanganyika Territory, carried out by the Survey Division, Department of Lands and Mines: Roy. Astron. Soc. Monthly Notices, Geophys. Suppl., vol. 4, no. 1, pp. 94-113, London, 1937.

The equipment consisted of a vacuum chamber in which two pendulums could be swung in opposite phase, three invar pendulums, a chronograph, a wireless set, and a vacuum pump. The method consisted essentially in swinging two pendulums in the field and two at a base station in England simultaneously for periods of approximately 1 hour. The same wireless Morse message is recorded at the base and in the field, and the periods of the two sets of pendulums are compared by finding how many times each swings between two chosen points in the Morse message. The field pendulums having previously been standardized in England, their change in period can be found, and from it the difference in $g$ between the field station and the place where the standardization was made can be computed. The records are made on bromide paper fixed on a chronograph drum. The apparatus as a whole gave satisfactory results. The results of the standardizations and of measurements in Africa are shown in a table. Comments on certain observations given in the table are made. The computed attractions of topography and the mean heights of the zones are shown in two tables. The isostatic anomalies are very much less than the Bouguer ones, showing that East Africa as a whole is very nearly in isostatic equilibrium. Maps showing the free-air anomalies, Bouguer anomalies, and isostatic anomalies on Hayford's hypothesis are added.W. $A$. 
3662. Jeffreys, Harold, On the figures of the earth and moon: Royal Astron. Soc. Monthly Notices, Geophys. Suppl., vol. 4, no. 1, pp. 1-13, London, 1937.

De Sitter's theory of the figure of the earth is somewhat unsatisfactory because it assumes hydrostatic conditions within the earth, which do not hold. It has been corrected for the relativity effects, and it is found that the main ellipticity effects, at any rate, do not show significant departures from the theory. A rediscussion of the data for the moon's motion has been carried out, using only the theory of the field outside the earth. A geophysical analogy shows that the moon must be nearly homogeneous. The data are found to be consistent with the value $0.87 \pm 0.06$ for the ratio $f$ in the moon; the earth's ellipticity is found to be $1 / 296.38 \pm 0.51$, and the corresponding gravity formula is

$$
G=978.051\left[1+(0.005282 \pm 0.000006) \sin ^{2} \phi-0.000007 \sin ^{2} 2 \phi\right]
$$

It is believed that the apparent accuracy of this formula is genuine as far as the term $\sin ^{2} \phi$ is concerned, and that other formulas may be in error by larger amounts on account of failure of the methods of analysis to allow for other terms. The ratio $c / M b^{2}$ for the earth is $0.3345 \pm$ 0.0012 . The ellipticities of the moon have been evaluated. It appears that their high values cannot be explained on the supposition that the moon solidified when already keeping the same face to the earth, but they can be explained if it was rotating freely in about 3.5 days.Author's abstract.

3663. Lagrula, J., Mesures de l'intensité de la pesanteur effectuées en Afrique du Nord durant l'année 1936 [Measurements of the intensity of gravity carried out in North Africa during 1936]: Acad. sci. Paris Comptes rendus, vol. 204, no. 2, p. 108, 1937.

The results of measurements made with Holweck-Lejay pendulum are given in a table. They may be slightly incorrect, because the topographic effect was not taken into consideration and because some figures: adopted for the altitudes and densities were not revised. However, this would not change the course of the isanomal curves. Attention is called to the phenomenon that the anomaly, negative in the interior of the earth, which is in conformity with the present theories of isostasy, has a minimum (of the order of -100 milligals) in the region of the Sahara mountain range. To the south of this range the anomalies are considerably smaller (Taghit, -17 ; Béni-Abbès, -26 ; Ghardaia, $-4)$. The positive anomaly near Touegourt $(+41)$ must be explained by the proximity of the bay of Gabès. $-W . A$.

3664. Lambert, W. D., The analogue of Stokes' formula for the Prey and Bouguer gravity anomalies: Gerlands Beitr. Geophysik, vol. 49, no. 1/2, pp. 199209, Leipzig, 1937.

The opinion has been expressed that the Prey and Bouguer anomalies are unsuited to a determination of the figure of the earth; on the other hand, the Prey anomaly has been recommended by Hopfner in connection with Stokes' formula, unchanged, for the determination of the undulations of the geoid. Malkin has shown, however, how Stokes' formula must be modified if Prey's anomalies are used. Another proof is here given of Malkin's formula, with special attention to the physi- 
cal dimensions of the quantities occurring in it and to the harmonic terms of degreés zero and unity; the latter results in a slight modiflcation of Malkin's formula. A similar formula is given for the Bouguer anomaly. The numerical values of the additional terms that occur in the modifled Stokes' formula may readily be determined from the tables of Special Publication no. 199 of the U. S. Coast and Geodetic Survey, "Tables for determining the form of the geoid and its indirect effect on gravity", by W. Lambert and Fr. Darling (Geophys. Abstracts 84 , no. 3093). These corrections are so large and in practice so uncertain as to make the use of either the Prey or the Bouguer anomaly undesirable for determining the figure of the earth. References are given to articles setting forth why the isostatic anomaly is preferable.Author's abstract.

3665. Lejay, P., Measurements with Holweck-Lejay gravimeter: Acad. sci. Paris Comptes rendus, vol. 203, no. 1, pp. 13-16, 1936.

A table of values of $g$ measured at 57 stations by apparatus 42 is given. Measurements were repeated by apparatus 510. Both observations agreed well one with another. The precision was about 2 milligals.$: \quad: \quad W \cdot A$

3666. Lettau, Heinz, Das Horizontaldoppelpendel [The horizontal double pendulum] : Zeitschr. Geophysik, vol. 13, no. 1, pp. 25-33, Braunschweig, 1937.

- A clinometer of high sensitivity (horizontal double pendulum) can be arranged by the mechanical coupling of two horizontal pendulums. From the condition of equilibrium the condition of stability is reached ly the coupled system, which combines the maximum magnification attainable by the horizontal double pendulum with the external measurements and masses of a single pendulum. A horizontal double pendulum was used at the Geophysical Observatory of the University

$\therefore \ldots$ : of Leipzig for registration of earth tides and of the bending of the .. uppermost earth's crust caused by barometric and thermal changes in

$\therefore:$ the atmosphere. The sensitivity of the instrument made it possible

$\therefore$ to read on the recording paper arcs of $10^{-4} \mathrm{sec}$. (with a light path of

$\because \because$ only $2 \mathrm{~m}$ ) notwithstanding the fact that a disturbing effect was produced on the instrumental errors owing to the installation of the instrument on the floor of a room which was visited daily.-Author's abstract, translated by. W. A.

3667. Leushin, P. I., Brief report on the work of the Transcaucasian Gravimetrical Expedition of 1931 [in Russian] : Acad. sci. U. R. S. S., Inst. Séismol., Pub. 67, pp. 54-56, 1935.

The Lennox-Conyngham pendulum apparatus was used, and observations were made on 19 stations. The following conclusions are drawn: (1) The great negative anomalies in the valley of the Kura River cannot be explained only by the presence of light conglomerates, sands, and other alluvial materials. The causes producing the anomalies must lie at greater depths. (2) From the curve of the gradients of gravity the fact is established that the probable seismic phenomena occur in the regions with greater gradients; this is proved by the data obtained from other sources. (3) The observations obtained confirm the assumption, expressed by several geophysicists, that in all ollbearing regions negative anomalies are observed. $-W$. $A$. 
3668. Miller, A. H., and Hughson, W. G., Gravity and isostasy in Canada: Dominion Observatory, Pub., vol. 11, no. 3, pp. 81-134, Ottawa, 1936.

About one-third of Canada has been covered by 128 gravity stations established in the southern part of Canada and in the basin of the Mackenzie River. Reductions by the free-air, Bonguer, Hayford, and Airy methods show that the area as a whole is in practically complete isostatic equilibrium. This also applies to British Columbia and to the mountainous part of Alberta. The results agree somewhat better with the Airy than with the Hayford reduction. The most probable depths for both methods have been computed separately for 22 stations in the mountains as well as for 126 stations; the total number was reduced isostatically. All the important results are tabulated and are in part shown graphically in two curves and on a gravity map which shows the anomalies for both United States and Canadian stations.-Authors' abstract.

3669. Miyabe, Naomi, Preliminary notes on experimental studies on the plastic deformation of soil: Tokyo Imp. Univ., Earthquake Research Inst., Bull., vol. 14, no. 4, pp. 543-552, 1936.

In these preliminary notes on experiments in connection with deformation of soils, the modes of deformations within the limit of their breaking strengths are explained by assuming a visco-elastic property for the soil as expressed by Maxwell's formula. As to the points left unexplained, of which there are a number, it is hoped that it will be possible to deal with them in a future investigation, particularly as there may be some points in the physical and chemical properties of soil that could be discusșed in connection with its colloidal nature. The results of such studies will be closely related to a number of problems in geophysical phenomena-for instance, oscillations of surface layers, the remarkable local subsidences, etc.-Author's abstract.

3670. Miyabe, Naomi, On the degree of disturbance of the earth's crust: Tokyo Imp. Univ., Earthquake Research Inst., Bull., vol. 14, no. 3, pp. 387-398, 1936.

In this paper the writer has calculated the values of $\sqrt{\overline{\Delta^{2}}}$ representing the degree of disturbance of the earth's crust, where

$$
\sqrt{\Delta^{2}}=\sqrt{\left[\frac{\left.W_{n+1}-\bar{W}_{n}\right]^{2}}{t}\right.}
$$

and $W_{n}$ is the vertical displacement of the $n$th benchmark during the period $t$, and discusses its variation with respect to time. The results of the present study are summarized as follows:

1. In regions where the earth's crust has once been greatly disturbed by destructive earthquakes; the values of $\sqrt{\overline{\Delta^{2}}}$ decrease exponentially.

2. In regions where the earth's crust has not been greatly disturbed by earthquakes, the values of $\sqrt{\prime \overline{\Delta^{2}}}$ remain approximately constant.

3. This decrease in the values of $\sqrt{\overline{\Delta^{2}}}$ after an earthquake or volcanic eruption may be due to variations in the mobility of the earth's crust or crustal blocks.

4. The discussion is based on the assumption that the degree of disturbance along a line of levels represents that of the region under consideration-that is, if in said region its horizontal dimensions were 
properly limited, the crustal disturbance would be uniform, and the translational and tilting movements of crustal blocks in that region will be at random.-Author's abstract.

3671: Munsey, D. F., and Bullard, E. C., Gravity measurements in the AngloEgyptian Sudan: Royal Astron. Soc. Monthly Notices, Geophys. Suppl., vol. 4, no. 1, pp. 114-121, London, 1937.

A series of gravity measurements that were made along a line from Khartoum to Suakin is described. Two invar pendulums were used at all the stations, and a third pendulum was compared with them occasionally. The results of observations are shown in tables which give the differences between the periods of the field and base pendulums, the attractions of topography, the mean heights of the zones, and all the gravity measurements so far made in the Sudan. The isostatic anomalies on Hayford's assumptions with a depth of compensation of $113.7 \mathrm{~km}$ and a section along a line from Khartoum to Suakin are shown in two figures. It is established that the assumption of isostasy gives positive anomalies over the Red Sea and its coasts, but that these anomalies do not extend far into the Sudan. The most natural explanation assumed is that there is a genuine departure from isostasy and that the Red Sea is underlain by a mass of heavy rock. The main conclusion drawn from the gravity work is that the Red Sea is different from the other parts of the African Rifts, but the cause of the difference is not known.-W. $A$.

3672. Peterson, R. A., Instrument for rapid measurenient of gravity [abstract]: Geol. Soc. America Proc., June 1936, p. 340.

The common pendulum, swinging on a knife-edge suspension, has been and probably still is the most precise and reliable instrument for the measurement of relative values of gravity. Since the time required for an observation is rather long, considerable. effort has been expended in devising more precise and rapid methods of timing. These efforts have also stimulated the construction of other types of gravity instruments, several of which have been described in the last few years. Noteworthy among these is the Holweck-LeJay apparatus, which consists of an inverted pendulum swinging on an elastic suspension at its lower end. The time required for an observation is only a few minutes. A Holweck-Lejay pendulum constructed by the author is briefly described, and some preliminary results of gravity determinations are given.-Author's abstract.

3673. Schwinner, Robert, Die Schwere in den westlichen Karpaten [Gravity in the western Carpathians]: Gerlands Beitr. Geophysik, vol. 49, no. 3. pp. 260-276, Leipzig, 1937.

The foreland of the western Carpathians shows uniform positive anomalies of gravity (Bouguer reduction). The outer folded zone of the Carpathian sandstone in contrast has negative anomalies of about -50 milligals. The sandstone is lighter than the adjacent crystalline rocks, and the "roots of the Fold Mountains" (sial) have been embedded in the heavy sima, producing a deficiency of mass. The mountains may be partly in isostatic equilibrium, but in most regions hydrostatic uplift probably prevails. The zone of the "Kerngebirge" has on an average the same positive anomalies as the foreland. The tectonically lifted nuclei have the greatest positive anomaly (Saxonic type). 
Adjacent to this district negative anomalies seem to characterize a mostly covered Hercynian belt of folding-"Zips-Gömörer Erzgebirge""island of Schemnitz"-district of the Raab, from the "inner belt" (innerer Gürtel) to East Styria. The adjoining, recent volcanic districts of central Hungary have highly positive anomalies, with heavy basic lavas and intrusions in the lower stratum.

The western Carpathians greatly resemble the northeastern Alps in gravity and seismic conditions (transversal earthquakes). They are distinguished from the Swiss Alps by the quite different gravimetric attitude of the autochthonous massifs.-Author's abstract.

3674. Stubbe, G., and Schmidt, K. H., Instruments and operating procedure in geophysical prospecting by gravity methods: Petroleum Engineer, vol. 8, no. 5, pp. 137-139, Dallas, Tex., 1937.

After a description of the torsion balance, gravimeter, and one type of a three-pendulum field apparatus and a discussion of their use, the authors give the following summary :

"At the present time the torsion balance is still the most practical and reliable instrument for detailed gravimetric surveys. In addition to giving all the data available by other methods, it has the advantage of sensitivity and stability of data obtained.

"The gravimeter undoubtedly will become more practical and useful as further improvements and developments are forthcoming. At the present time it seems that its activities are limited to surveys of a reconnaissance nature.

"The pendulum apparatus will be limited to studies of large areas and to work of scientific interest. In comparing gravity surveys with other methods, such as the seismic and magnetic methods, it may be mentioned that a study of the activity in any particular fleld reveals a cyclic character. Whether one method or the other is used should not depend so much on whether one method may be popular at the time, but rather upon the conditions that present themselves in the area to be surveyed. In fact, multiple methods of investigation should offer. much and are becoming recognized as good exploration policy. The position of gravity surveys fits well into this picture, for the method is recognized to be valuable in broad as well as detailed studies, and operating costs are not prohibitive." $-W . A$.

3675. Swick, C. H. Gravity in southeastern Virginia : Am. Assoc. Petroleum Geologists Bull., vol. 21, no. 3, pp. 333-339, 1937.

During the summer of 1936 the United States Coast and Geodetic Sur. vey made gravity determinations at 16 stations in Virginia along practically a straight line from the vicinity of Petersburg to the coast southeast of Norfolk. The work was requested by Professors Miller and Ewing, of Lehigh University, and follows closely a line of seismic determinations made by the latter. The results were reduced by the isostatic method, and a profile of isostatic anomalies was thus obtained. The observed values of gravity and other essential data for the stations are given in a table and the results are discussed briefly. The gradual downward slope of the gravity profile toward the east corresponds approximately with the slope of the basement rocks but is somewhat steeper than would be expected from this cause alone unless a very low density is assumed for the overlying material.-A thor's abstract. 
3676. Szecsödy, N., and Renner, J., Ein einfaches Instrument zur Erlẹichterung der Gravitationsberechnungen [A simple rinstrument to facilitate gravity calculations] : Beitr. :Angew. Geophysik, vol. 6, no. 3, pp. 307-310, Leipzig, 1937.

An instrument is described for calculating the gravitational effect of two-dimensional subterranean disturbing 'masses.' This instrument consists of a protractor and two rulersi with logàrithmic scales. The protractor is divided in radians. One of the rulers is an extension of the protractor; the other can be turned around the center of the protractor. For calculating the effect of a subterranean slope on a certain point $P$ of the earth's surface with the inclination angle $a$ the angle $\beta$ is determined by the protractor and the difference $L=i n r_{2}-i n r_{1}$ by the rulers. Using these quantities, the gradient as well as the curvature data can be easily computed, as is shown in a table. An advantage of this method is that the same readings can be used for gradient and curvature data.-Authors' abstract.

3677. Thyssen, Stephen von, Über die Anwendungsmöglichkeiten insbesondere von relativen Schweremessungen in westdeutschen Steinkohlgebieten [On the possible application of relative gravity measurements in west German coal fields]: Beitr. angew. Geophysik, vol. 6, no. 3, pp. 319331, Leipzig, 1937.

Ten years ago measurements of gravity were carried out with the aid of the torsion balance in the west German coal fièlds. It was found that the ridges and valleys of the productive layers could be mapped in this way. Thanks to the high accuracy of the Thyssen gravimeter, relative gravity measurements can now be utilized in the same way. Ridges are found to be regions of a gravimetric uplift, and valleys to be regions of a gravimetric depression. Post-Carboniferous disturbances of sufficient size can also be located by means of gravimetric cross sections. The folds and faults of the productive Carboniferous layers alone cannot account for the measured variations of gravity. It is supposed that the disturbances originate deeper down in the Devonian layer. Hence, the gravimetric map does not always show the Carboniferous ridges and valleys in their true position; there may be slight displacements. The examples recorded in this paper show the usefulness of relative measurements made with a highly accurate static gravimeter in the study of the tectonics of the west. German coal fields. The method can be applied only in a region where post-Carboniferous disturbances prevail.-Author's abstract, translated by $W . A$.

3678. Van Bemmelen, R. W., The undation theory of the development of the earth's crust: Reprint from 16th Internat. Geol. Cong. Rept., 18 pp., 1935 .

The process of crustal development is only a small link in the chain of cosmic evolution and therefore is subject to the general laws of thermodynamics. The cooling of the earth follows from the second law of thermodynamics. This cooling affects mainly the outer 100 to 120 kilometers, where the primeval silicate melt is differentiating. This differentiation disturbs the thermal and gravitational équilibrium of the parent magna (equilibrioturbal action). Subcrustal mass dis- 
placements: work toward readjustment of this equilibrium (equilibriopetal reaction). These subcrustal mass , displacements are accompanied by uplifts and subsidences at.the surface: (undations). These undations are in turn equilibrioturbal for the gravitative equilibrium in the outer crust and cause sliding and folding of strata. Yolcanism, earthquakes, and gravity anomalies are other consequences of this magmatic differentiation and these subcrustal mass displacements. The displacements of the earth's crust are thus the result of the reciprocal effect of equilibrioturbal magmatic differentiation and equilibriopetal gravitative adjustment.-Author's abstract."

\section{MAGNETIC METHODS}

3679. Eblé, Louis, Valeurs des élémenț magnétiques a la station du Val-Joyeux (Seine-et-Oise) au $1^{\text {er }}$ janvier 1937 [Values of magnetic elements at the station of Val-Joyeux on January 1, 1937] : Acad. sci. Paris Comptẹs rendus, vol. 204, no. 11, p. 875, 1937.

Values of magnetic elements were deduced from the hourly values registered during December 1936 and January 1937. They are shown in a table. Secular variations resulted from the differences between the values of the elements established for January 1, 1937, and January 1, 1936.-W. A.

3680 Gibsone,.. John, Vertikalmagnetische Messungen in der Umgebung von Hamburg insbesondere ïber den Horsten von Stade, Lieth-Elmshorn, Segeberg und Lüneburg [Measurements of the vertical intensity of the earth-magnetic field in the vicinity of Hamburg, especially above the horsts of Stade, Lieth-Elmshorn, Segeberg, and Lüneburg]: Beitr. physikal. Erforschung der Erdrinde, no. 8, 36 pp., Berlin, Preussische geologische Landesanstalt, 1935.

This paper shows that the geologic and topographic picture of the surface surveyed is probably in closer agreement with the geologic and tectonic conditions of the subsurface than was previously assumed. It was not possible to establish whether the total regional magnetic field, as determined by the survey, was produced by one or several crystalline magnetic horizons in rocks adjoining or lying above one another. The causes of the many local magnetic anomalies found superimposed on the regional magnetic field in the region of measurements could not be ascertained, but it is shown that such detailed measurements reveal the main structural elements of the subsoil. On the basis of such surveys the geologist will be able to establish in regions with Tertiary and Quaternary overburden-as; for example, the whole of north Germany - where in the region he may expect to find disturbed or undisturbed layers of the Mesozoic and Cenozoic rocks. How the horsts are connected with the system of the lines of disturbance may also be seen.-Author's abstract, translated by W. $\boldsymbol{A}$.

8681. Hameister, Ernst, Die Verteilung der lokalen Magnetisierung in Hessen fiir die Epoche 1911.0 [The distribution of 'the local magnetization in Hessen for the epoch 1911:0] : Gerlands Beitr. Geophysik," vol. 49, no. 1/2, pp. 66-70, Leipzig, 1937.

The local magnetization is calculated and the results presented on a map. Values for the stations measured are given in a table.-W. $A$. 
3682. Hasegawa, Mankiti, Analysis of the field diurnal variation of terrestrial magnetism of the different types: Imp. Acad. Japan Proc., vol. 12, no. 8, pp. 221-224, Tokyo, 1936.

The paper gives a summary of the results of a mathematical analysis of the diurnal magnetic variations over the earth; based on data obtained from an extensive and world-wide series of magnetic observations.-W. $A$.

3683. Hasegawa, Mankiti, Representation of the field of diurnal variations of terrestrial magnetism by the method of graphical integration: Imp. Acad. Japan Proc., vol. 12, no. 8, pp. 225-228, Tokyo, 1936.

Graphic integration is applied to illustrate the fleld of diurnal magnetic variations at every hour in studying the progress of its changes. Maps showing the equipotential lines of the diurnal magnetic variations are given.-W. $A$.

3684. Hazard, D. L., and McFarland, W. N., Magnetic declination in the United States, 1935: U. S. Coast and Geodetic Survey Serial Pub. 592, March 1937.

The distribution of the magnetic declination and its annual rate of change for the first part of 1935 are shown graphically on an isogonic chart. The change of declination is given in tabular form for places distributed over the whole country at intervals of $2^{\circ}$ of latitude and longitude. Methods of determining the true meridian are explained.W. A.

3685. Molin, Kurt, A general earth-magnetic investigation of Sweden, pt. 1, Declination: Sveriges geol. Undersökning, ser. Ca, no. 25, Stockholm, 1936.

During earth-magnetic investigations in Sweden, carried out during 1928 to 1934 by the Geological Survey of Sweden, the earth-magnetic elements $\mathrm{D}, \mathrm{H}$, and $\mathrm{I}$ were measured at 2,359 points, evenly distributed over the country. Detailed descriptions of all the field stations are collected in archives. The instruments used were magnetic theodolites: Askania no. 84065, Chasselon no. 83, Bamberg no. 2312, Bamberg no. 12014 ; dip circles: Dover no. 60, Dover no. 72, Dover no. 230, Casella no. 2005 , and the Ad. Schmidt vertical field balance. Original maps for isogones and anomalies of declination are made on a scale of 1:400,000. The lines of equal declination and those of equal anomaly are computed by means of a linear interpolation. For the whole country the negative anomaly has a surplus of 5.9 percent. The locations of the most characteristic regional anomalies (negative and positive) are given. Maps are added showing anomaly of declination, lines of equal anomaly of declination, magnetic declination, and anomaly of declination in Skåne.-W. A.

8686 Orkisz, Henryk, Magnetic survey carried out in 1933 in the vicinity of Truskawiec [in Polish] : Univ. Lwow, Inst. géophysique et météorologie, Communications, vol. 8, no. 98, pp. 114-122, 1936.

Magnetic anomalies of the vertical component observed in 1933 in the region of Truskawiec are shown in a map. The isanomalies are traced with intervals of $5 \gamma$. On another map are shown the geologic features of the Carpathians, isohyps of the Boryslaw sandstones, outcrops of overlapping overthrusts, and the main transversal faults.W. A. 
3687: Orkisz, Henryk, Magnetic observations made in 1933 and 1934 in Jànow [in Polish]: Univ. Lwow, Inst. géophysique et métérologie, Communications, vol. 8, no. 102, pp. 190-213, 1936.

The results of observations made at the station in Janow in 1933 and 1934 are shown in tables 1 and 2 . The mean values of $\mathrm{D}, \mathrm{H}, \mathrm{Z}$, and the magnetic characteristics for each day are given in table 3 . The diurnal variations of $\mathrm{D}, \mathrm{H}, \mathrm{Z}$ are represented for each month in tables 4 to 9 , including the observations made during the days of disturbance. Mean diurnal curves, as well as those representing the disturbed days, are given in flgures. $-W$. $A$.

3688. Orkisz, Henryk, Hysteresis in the magnetic balance of the magnetometer [in Polish] : Univ. Lwow, Inst. géophysique et météorologie, Communications, vol. 8, no. 107, pp. 301-304, 1936.

After the installation of the magnetometer at the station of Janow the temperature compensators were adjusted. The thermal coefficients were determined after a period of 1 year by statistical computations. Only temperature changes at certain frequencies were affected by these. thermal coefficients. The $\mathrm{Z}$ balance indicated the hysteresis at $\mathbf{a}$. frequency of 15 days. Temperature curves and $Z$ curves are shown in flgures. By eliminating the diurnal anomalies of $T$ and $Z$ and $b y$ tracing the $Z$ curve as a function of $T$, diagrams characteristic for: thermal hysteresis were obtained. This fact is probably due to an: insufficient adjustment of the balance system.-Author's abstract, translated by W. A.

3689. Orkisz, Henryk, Note concerning some deficiencies of the recording declinometer [in Polish]: Univ. Lwow, Inst. géophysique et météorologie, Communications, vol. 8, no. 108, pp. 306-309, 1936.

Notwithstanding a quasi-hermetical adjustment of the instrument, a very small cavity was formed between the magnet and the lower wall in the recording declinometer at the station of Janow. At the beginning of the warm season, in May and June, this defect caused a reduction of the diurnal amplitude and an apparent drift toward the west. The reduction from the main maximum amplitude, which coincides with the maximum of the temperature of the diurnal variation, is shown in a figure. The mean values of the amplitudes of the diurnal course and the probable real values are represented in a figure. By. using the equation derived in this connection, the mean values of the real diurnal course may be calculated. The corrected course is shown in the figure.-Author's abstract, translated by W. A.

3690. Rayner, J. M., Report on magnetic prospecting at Tennant Creek: Areal, Geological, and Geophysical Survey of Northern Australia Rept. 4, Northern Territory, 25 pp., June 1936.

After a description of the location of the Tennant Creek gold field and a brief note on the principles of the magnetic method of prospecting, the results of magnetic surveys in the Eldorado, Great Eastern, Rising Sun, and Wheal Dorea areas and of the tests of schist combs: are described, and the following conclusion is drawn: "As anticipated, intense magnetic effects have been found arising from the hematite bodies of Tennant Creek. Further, a number of significant magnetic anomalies, considered to be due to hematite bodies, have been found in areas where there is no surface evidence of ironstone. The most 
spectacular anomaly is that northwest of the Eldorado mine.

There is only the most indirect evidence for supposing that it is likely to be auriferous. *** Of the other anomalies discovered, some * * are being tested at present, * * * but so far no results have come to hand. Arrangements will be made to test the more favorable indications on other areas. *** During the coming field season the survey will be continued upon a rather bigger scale and a further report prepared in due course. Consideration is being given to the possibility of employing the electrical and gravimetric methods of prospecting on this fleld."-W. $A$.

3691. Roman, Irwin, and Sermon, T. C., Some magnetic gradiometer developments during 1934-35: Am. Geophys. Union Trans. 16th Ann. Meeting, pp. 181-188, 1935.

In a previous paper, "A magnetic gradiometer" by the same authors (Am. Inst. Min. Met. Eng. Tech. Pub. 542, 1934 ; Geophys. Abstracts 60, no. 1847), an instrument was described for measuring the ratio of the magnetic intensity components at two nearby points. In the present paper an attempt has been made to bring the status of the magnetic gradiometer to date. A description and photographs of the instrument are given. $-W$. $A$.

3692. Siemens, Günter, Erdmagnetische Untersuchung der Elbtalzone zwischen Torgau und Dresden [Earth magnetic investigations of the Elbe Valley zone between Torgau and Dresden]: Beitr. physikal. Erforschung der Erdrinde, no. 7, 53 pp., Berlin, Preussische geol. Landesanstalt, 1935.

Considerable disturbance was observed in this zone. Magnetic methods were used for clearing up the geologic structure. Three more or less separated masses of plutonic rocks could be distinguished on the map of isanomalies. From the course of the isanomalies information on the form and depth could be obtained. In order to draw conclusions, the assumption was made that the magnetite formation in the magma occurred during the intrusion in the shallow zone of earth's crust.-W. $A$.

3693. Soske, J. L., Magnetometer survey of the southern portion of the San Andreas fault [abstract]: Geol. Soc. America Proc., June 1936, p. 340.

Five vertical intensity profiles were made across the surface trace of the San Andreas fault between Whitewater Canyon and Coachella. The position of the fault trace in this area is clearly marked by a slightly curved and almost continuously traceable chain of low scarps, ridges, and elongate depressions, most of which involve Quaternary

$\therefore \quad$ alluvial deposits and afford unmistakable evidence of recent earth

$\therefore \quad \therefore$. movements. At the five places where profles cross the fault trace magnetic anomalies typical of such a structure were observed. The fault anomalies are of sufficient magnitude to be very conspicuous, and the positive nature of the results stimulated further magnetic work as a possible means of determining the position of the fault beyond the point where its trace is obscured by alluvial overburden and lost in complexity of crustal structure. Six additional profiles were made across the trend of the great tear fault south of Coachella. The observed anomalies indicate that the fault passes through the northeast portion of the sink and beyond the south end of the Salton Sea.Author's abstract. 
3694. Stagg, J. M., Aspects of the current system producing magnetic disturb-, ance: Roy. Soc. London Proc. A, vol. 152, no. 876, pp. 277-298, 1935.

The three mutually perpendicular force vectors of the earth's magnetic field added during disturbance to those acting on quiet days are examined. From the characteristics in magnitude and orientation of these disturbing vectors at seven observatories it is found that the overhead current system producing the regular diurnal disturbing field in moderately high latitudes is primarily concentrated in a narrow zone asymmetrically encircling the magnetic axis pole and at about $23^{\circ}$ from it. The direction of this current flow is east-west in the early local morning and a maximum. in the reverse direction at about 18 hours. A systematic daily change of space distribution and azimuth of the lines of current flow accompanies the change in current direction. In winter the disturbance vectors further indicate that the current zone lies more northerly than in summer, but the seasonal displacement, like the daily, is probably to be attributed more to a changed distribution in the vertical of the lines of current flow than to a horizontal movement of the whole system. At all times the disturbing system is diffuse and complex.-Author's abstract.

3695. Thellier, Emile, Aimantation des terres cuites; application a la recherche de l'intensité du champs magnétique terrestre dans la passé [Magnetization of baked earths; application to the research of the intensity of the terrestrial magnetic field in the past] : Acad. sci. Paris Comptes rendus, vol. 204, no. 3, pp. 184-186, 1937.

An argillaceous mass baked in a magnetic field retains, after cooling, a feeble permanent magnetization which is very stable. The question is raised whether the terrestrial field of a given epoch can be gaged from the magnetic properties of baked earths baked during the same epoch. Values are given for the specific magnetization of earths baked in different atmospheres at different temperatures. The following results are stated: When a magnetized baked earth is reheated in zero magnetic field, its magnetization disappears at $\mathrm{T}=580^{\circ} \mathrm{C}$. or $670^{\circ}$ C. During the initial baking in a magnetic field the earth becomes magnetized only between the temperature $T$ and ordinary temperatures. The magnetization of an earth baked at a high temperature is exactly the same when the fleld is applied during heating and cooling and when it acts only during cooling from $670^{\circ} \mathrm{C}$. If an earth baked at a high temperature acquired a magnetization $\sigma$ in a field $\mathrm{H}$, and is reheated in a neutral atmosphere to $670^{\circ} \mathrm{C}$. (demagnetized), then cooled in the same field $\mathrm{H}$, it assumes a new magnetization $\sigma^{\prime}$, but very often $\sigma^{\prime}=\sigma .-$ G. E. A., Sci. Abstracts, vol. 40, no. 472, $199 \%$.

3696. Thellier, Émile, Sur l'aimantation dite permanente des basaltes [On the permanent magnetization of basalts]: Acad. sci. Paris Comptes rendus, vol. 204, no. 11, pp. 876-879, 1937.

Samples of basalt from several places in Auvergne taken according to the procedure explained in a previous article (Geophys. Abstracts 87 , no. 3291) were investigated, and the values of the declination $D$ and inclination $I$ of the magnetization at the place of their origin were determined for each piece. The values were found not to be constant and were dependent on the influence of the terrestrial magnetic field. The presence of permanent magnetism in the samples was established and was assiumed to be due to the magnetite in the basalts. $W . A$. 
3697: Uhrig; L. F., and Schafer, Sidney, Observed and calculated values of the: magnetic intensity over a major geologic structure:- Gerlands Beitr. Geophysik, vol. 49, no. 1/2, pp. 129-139, Leipzig, 1937.

The authors compare the observed and calculated values of the vertical and horizontal components of the magnetic field along a profile across the Los Angeles Basin. A structural geologic cross section compiled from seismic, gravity, and geologic data was used as a basis for calculating the magnetic field. In the San Pedro Hills portion of the cross section, the calculated and observed values disagree, indicating that the granitic basement rocks lie at greater depths than shown in the structure section.-Authors' abstract.

3698. Wilson, C. W., Jr., and Born, K. E., The Flynn Creek disturbance, Jackson County, Tenn.: Jour. Geology, vol. 44, no. 7, pp. 815-835, 1936.

A small intensely disturbed area in Jackson County, Tenn., has been mapped and studied in detail. All the data accumulated indicate a cryptovolcanic origin of the structure. A magnetometer survey showed a well-developed magnetic high offset 4 miles to the south-southwest. The history of this disturbed area is interpreted as follows: Shortly preceding Chattanooga deposition an explosion took place near the surface, blowing out a crater 2 miles in diameter and 300 feet deep. The Ordovician limestones forming the floor and walls of this crater were shattered into breccia composed of angular fragments of varying sizes embedded in a matrix of smaller fragments and "rock flour." The deeper parts of the crater were filled with redeposited breccia, either as talus breccia or as bedded breccia deposited in a fresh-water lake that occupied the crater at one time. The Chattanooga sea invaded central Tennessee and filled the crater with black mud, now represented by about 250 feet of black shale. Fort Payne chert was later deposited upon the relatively smooth surface of the black shale.-Authors' abstract.

\section{SEISMIC METHODS}

3699. Angenheister, G., Earth vibrations: Ergebnisse exakten Naturwiss., no. 15, pp. 310-364, 1936.

Methods are given by which vibrations are excited in the earth, whether naturally or artificially, with descriptions of the instruments used for artificial production, and for their recording. This is followed by an account of the various waves produced by earthquakes or otherwise, with the effect thereon in causing reflection and refraction by discontinuities in the earth's crust and core. The inferences to be drawn from waves caused by suitably placed explosions as to the structure of the crust are described in considerable detail, with a table of velocities of waves mechanically produced in various sedimentary rocks of de posits.-C. A. S., Sci. Abstracts, vol. 40, no. 470 .

3700. Bois, Charles, Comparaison entre les valeurs de la profondeur focale des tremblements de terre déterminées à l'aide des tables de Wadati et celles obtenues an moyen des courbes de Brunner [Comparison between. the values of focal depths of earthquakes determined with the aid of Wadati's tables and those obtained by means of Brunner's curves]: Acad. sci. Paris Comptes rendus, vol. 204, no. 8, pp. 608-610, 1937.

The focal depths of $\mathbf{1 7}$ quakes were calculated from the data recorded in Strasbourg by using Wadati's tables and Brunner's curves. The 
results obtained by using Brunner's curves were greater than those obtained from Wadati's tables by an average of 25 kilometers. This difference is explained as resulting from the fact that (1) Wadati used data obtained from earthquakes observed exclusively in Japan, while Brunner considered various epicentral regions, and (2) Brunner utilized Knott's methods, while Wadati employed the classical formulas given by Rudzki, Benndorf, and Wiechert-Herglotz. Concerning Japanese earthquakes, Wadati's tables furnish certainly more correct results than Brumner's curves. It is difficult to make a conclusion with regard to the other regions, but in making a comparison of the results obtained, by regions, the difference was found to be always the same, of the order of 25 kilometers. Thus, if the local anomalies interfere in modifying the velocity of propagation, their effect seems to be negligible in comparison with the sources of error due to the application of Inott's hypotheses. Therefore, Wadati's tables should be used for studying deep-focus earthquakes.-W. A.

3701. Caloi, P., Due nuori tipi di onde sismiche alla luce di una teoria del Somigliana [Two new types of seismic waves in the light of Somigliana's theory] : Accad. Lincei Rend., vol. 23, no. 7, pp. 507-511, 1936.

According to Somigliana, seismic waves consist of superimposed longitudinal and transverse oscillations. The conditions necessary for the propagation of these waves in a lerel ground with equal surface velocity lead, for a relocity identical to that in the Rayleigh equation, to $\mathbf{x}$ conditional equation of third degree. This equation may have three real roots, one of which, lyirig between zero and 1 , corresponds to the Rayleigh waves. It was rot possible to find wares corresponding to the two other solutions of the conditional equation for the value of Poisson's constant equal to 0.25 . According to Matuzawa, the Poisson constant may have smaller values in the earth's upper layers. On the other hand, a new long-period surface wave having a velocity equal to $4.5 \mathrm{~km} / \mathrm{sec}$. was found by Gutenberg (G-wave). Another longperiod wave with a relocity of $6.5 \mathrm{~km} / \mathrm{sec}$. was found by the author (C-wave). It is possible to adjust these two waves to the two other real solutions of the conditional equation by using the value of 0.17 for the Poisson constant which was determined by Matuzawa in the earth's upper layer.-Schön's abstrict in Zeitschr. Geophysik, vol. 19, n.o. 1, 1987, translated by W. A.

3702. Einaudi, Renato, Una nuova interpretazione delle onde sismiche [A new interpretation of seismic waves]: $R$. accad. sci. Torino Atti, vol. $\mathbf{7 1}_{\text {, }}$ no. 2, pp. 299-309, 1936.

The second main phase of the earthquake waves, consisting of horizontal-longitudinal and vertical oscillations propagated with a velocity of $3.7 \mathrm{~km} / \mathrm{sec}$, is explained for a homogeneous ground by means of Rayleigh's solution of elasticity equations. But the waves of the first main phase, consisting of horizontal-transverse oscillations propagated with a relocity equal to $4 \mathrm{~km} / \mathrm{sec}$, could not be explained by these solutions. Therefore the lithosphere was used as a basis for their explanation. The author shows that for a homogeneous ground a solution of the elasticity equations can also be given representing waves. of the first phase.-Schön's abstract in Zeitschr. Geophysil, vol. 1.9, no. $1,199 \%$, translated by.W. A.

$19084-38-3$ 
3703. Ewing, Maurice, Crary, A. P., and Rutherford, H. M., Geophysical investigations in the emerged and submerged Atlantic Coastal plain; part I, Methods and results [abstract]: Geol. Soc. America Proc., June 1936, p. 75 .

Seismic refraction measurements were made along a line extending from Petersburg, Va., through Cape Henry to the edge of the Continental Shelf. Three zones were distinguished, as follows:

1. A surface zone, composed of material in which the velocity of seismic waves is 5,000 to 6,000 feet per second. Its thickness increases from 400 feet near Petersburg to 1,800 feet near Fortress Monroe and then decreases to 500 feet near the edge of the Shelf.

2. A second zone, velocity 7,500 to 8,500 feet per second, absent west of Fortress Monroe, underlying the surface zone east of Fortress Monroe. Its thickness gradually increases eastward to about 11,000 feet near the edge of the Shelf.

3. A third zone, velocity 18,000 to 20,000 feet per second, which underlies the other two zones.

Land stations and sea stations give concordant results, and the seismic data are in satisfactory agreement with the data from the deep well at Fortress Monroe. A section is exhibited which shows in detail the results obtained between the edge of the Piedmont Plateau and the edge of the Continental Shelf.

Good seismic reflection records were obtained at several stations at sea, but the stations average about 5 miles apart, and a satisfactory correlation of reflecting horizons has not been accomplished.-Authors' abstract.

3704. Faltas, Fayek, Konstruktive Ermittlung einer geneigten Schicht ans Laufzeitkurven und Azimutabweichungen [Constructive determination of an inclined layer from travel-time curves and azimuth deviations]: Neue Deutsche Forschungen, Abt. Meteorologie u. Geophysik, 30 pp., Berlin, 1937.

After a brief discussion of geometric elements applied in seismic work a graphic method is examined by which the depth, direction of fault, and incidence of a plane border of a laver may be determined from travel times and amplitudes of the horizontal component of ground movements caused by explosive tests and represented by profiles shot in two directions. The method was applied by the Göttingen Geophysical Institute in the clas pit of a brickyard near Göttingen. The results agreed well with the mathematical evaluation of the observation data. Another graphic method is described in the appendix by which the position of the border surface may be determined when only the traveltime observations are available (one profile shot in two directions and another in one direction).--Author's abstract, translated by W. A.

3705. Grenet, G., Représentation du fonctionnement des seismographes électromagnétiques au moyen de circuits électriques équivalents; Applications [Representation of the working of electromagnetic seismographs by means of equivalent electric circuits; Applications] : Inst. et observ. physique du globe du Puy-de-Dome Bull. 8, pp. 63-68, Clermont-Ferrand, 1936.

The representation of the working of a seismograph by the use of equivalent electric circuits (of higher frequencies) permits oscillo- 
graphic studies of the properties of the equivalent electric circuits, the characteristics of which can be easily altered, instead of conducting direct studies on the shaking platform. The similarity between the electrical and mechanical systems of oscillation leads naturally to the idea of introducing an ensemble of oscillating systems similar to electric filters between the pendulum and the galvanometer of a seismograph. Author's abstract, translated by W. A.

8706. Gutenberg, B., and Buwalda, J. P., Seismic reflection profile across Los Angeles Basin [abstract]: Geol. Soc. America Proc., June 1936, p. 327.

A seismic reflection profile was run along the line of an earlier study in 1931, from the San Pedro Hills, south of Harbor City northenstward between Signal Hill and Dominguez Hills, across the basin axis, through West Coyote Hills and the Puente Hills south of Puente. The profile consists of four parts separated by faults. Southwest of Inglewood fault the reflections recorded from the deepest surface range from $31 / 2$ kilometers in the San Pedro Hills immediately south of Harbor City to 7 to 8 kilometers west of the Inglewood fault, crossed 1 kilometer (0.6. mile) swest of Los Cerritos. This deepest surface is presumably the granitic basement, because nowhere could deeper reflections be secured with increased charges of dynamite. Near the middle of the second block the deepest reflections occur at a maximum depth of 13-14 kilometers (45,000 feet) south of Bellflower beneath the synclinal axis in the upper formations, and at some thousands of feet less depth near the Inglewood and Norwalk faults. On the third block the deepest reflections rise from a depth of about 6 kilometers near the Norwalk fault southwest of La Mirada to about 5 kilometers depth near the Whittier fault. North of the Whittier fault the few shots fired indicate that the deepest reflecting surface lies between 2 and $3 \frac{1}{2}$ kilometer's in depth. The vertical offset at the Inglewood and Norwalk faults, loci of many earthquakes, of roughly 5 kilometers in the deepest reflecting surface, suggests strongly that the synclinal Los Angeles Basin is a graben at depth.-Author's abstract.

3707. Heiland, C. A., Reflection seismic instruments and their cliciency: Petroleum Engineer, vol. 8, no. 6, pp. 91-98, Dallas, Tex., 1937.

A description is given of the types now in prevalent use for the component parts of the recording "channel", which consists of three units(1) the electrical vibration detectors (pick-ups, or phones, or seismographs), (2) the amplifier, and (3) the galvanometer. No general formula is given regarding what type of pick-up, amplifier, or galvanometer should be used to obtain maximum efficiency; however, there are certain fundamental considerations that must be applied to reach greater efficiency. The necessity of obtaining the right balance in the sensitivities of the component parts is emphasized. It has been found that a high output of the pick-up and high galvanometer sensitivity are the most essential requirements and that a good measure for the efficiency of a seismic equipment is the over-all magnification obtained when the pick-up is connected without truck amplifier to the galvanometer. In field operations size and weight of the equipment are important considerations. The pick-up efficiency can be measured by the output (per unit of ground motion at reflection frequencies) for a given weight and size, and the galvanometer efficiency by its sensitivity (in millimeters of 
deflectiun per unit of current at reflection frequencies) for its weight and size. As a characteristic frequency $50 \mathrm{c}$. p. $\mathrm{s}$. is best chosen. The three different types of pick-ups and three different types of galvanometers now in general use are considered with respect to greatest efficiency. The inductive and reluctance types of detectors can be made into more efficient units than the capacitive and piezo-electric types. Of the recording galvanometers the oscillographs and coil galvanometers appear to be the most suitable types.-W. $A$.

3708. Heinrich, Bestimmung der Fortpflanzungsgeschwindigkeiten elastischer Wellen im oberschlesischen Karbon [Determination of the velocities of propagation of elastic waves in Upper Silesian coal] : Zeitschr. Berg-, Hïtten- u. Salinenwesen im Deutschen Reich, vol. 84, no. 10, pp. 436439, Berlin, 1937.

Velocities of propagation in sandstone and coal are determined by measurements underground; from these the corresponding $\mathrm{E}$ values (elasticity modulus) are calculated. It is shown that there are differences in the velocities of propagation of elastic waves, depending on the amount of work performed in various mines. The results obtained so far are not considered to be sufficient to permit drawing any general conclusions. A schematic design of the apparatus used is given.-W. A.

3709. Ishimoto, Mishio, and Iida, Kumizi, Determination of elastic constants of soils by means of vibration methods, part 1, Young's modulus: Tokyo. Imp. Univ., Earthquake Research Inst., Bull., rol. 14, no. 4, pp. 632-^j56, 1936.

1. The authors studied the elastic properties of soils of several regions in Tokyo, as taken out in the natural state from underground in Hongō, Maru-no-uti, and Komatugawa by means of boring. Specimens made into the form of rectangular prisms were tested in both the natural and recomposed states.

2. The longitudinal wave velocity $v$ in these soil specimens was obtained by means of the vibration method and then their Young's moduli $E$ were computed from the relation $E=\rho v^{2}(\rho=$ density).

3. The apparent effect of solid riscosity becomes great according io the variable height and variable moisture content of the soil specimen. The smaller the height and the moisture content of the specimen the more the resonance curves tend to flatten.

4. The solid viscosity coefficient $\gamma$ was determined by comparing the reducing curves obtained experimentally with the theoretical curves.

5. The longitudinal wave velocity, Young's modulus, and the solid viscosity coefficient of the soils in the natural state are greater than those obtained in the recomposed state.

6. The wave velocity, Young's modulus and the solid viscosity coefficient decrease somewhat rapidly with the increase of the moisture content. The coefficient of solid viscosity of these soils is of the order of $10^{4}$ to $10^{6}$ and the velocity varies from about 60 to $400 \mathrm{~m} / \mathrm{sec}$. at moisturecontent ranges of about 50 to 20 percent.

7. The frequency of the partials of the second maximum amplitude attains about three times that of the first. The observed vibration of the soil specimen can, therefore, be explained as the longitudinal vibration in a clamped and free-end bar.-From authors' summary and conclusion. 
3710. Jeffreys, Harold, The structure of the earth down to the $20^{\circ}$ discontinuity (second paper) : Royal Astron. Soc. Monthly Notices, Geophys. Suppl., vol. 4, no. 1, pp. 13-39, London, 1937. [For the first paper, see Geophys. Abstracts, 87, no. 3528.]

The observations used by Gutenberg and Richter as evidence against the discontinuity in $d t / d \Delta$ for $P$ at about $20^{\circ}$ agree somewhat better with my times than with theirs, and their mean apparent velocities show just such a distribution as would be expected if my times are correct. The observations of $S d$ in two deep-focus earthquakes have been found to agree well with prediction, using the solution already found. A number of particularly well observed earthquakes have been used to find a new set of travel times for $S$ and $S K S$, which appear trustworthy to about 2 sec., but some corrections for minor systematic errors still need to be made. Up to about $40^{\circ}$ they agree fairly well with the times of Gutenberg and Richter, on the supposition that the latter refer to a surface focus, but Gutenberg and Richter's 1935 times appear to be about 11 sec. too short at $80^{\circ}$ to agree with this hypothesis. It appears that $m y$ previous times for $S$ are fairly good up to $70^{\circ}$ but that at greater distances they are too long; the same applies to $S K S .-A u$ thor's abstract.

3711. Kawasumi, Hirosi, Theoretical and experimental study of initial motion of seismographs and the quantitative study of first impulsion of earthquake, part 1: Tokyo Imp. Univ., Earthquake Research Inst., Bull., vol. 14, no. 3, pp. 319-338, 1936.

The author discusses the initial motion of seismographs caused by ground motion of the shock type, with special reference to a simple method of reducing the first impulse of earthquake motion. The motion of ordinary seismographs as well as those of the Galitzin type caused by ground motion $\sigma$, where $\sigma=3 \sin p t-\sin 3 p t$, are theoretically calculated. Then, in actual application, the accuracy of this assumption as applied to other forms of ground motions is examined, and a simple method of reducing the first impulse of earthquakes with tolerable accuracy is pointed out. $-W . A$.

3712. Kawasumi, Hirosi, and Kinosita, Zyuniti, Theoretical and experimental study of initial motion of seismographs and the quantitative study of first impulsion of earthquake, part 2: Tokyo Imp. Univ., Earthquake Research Inst., Bull., vol. 14, no. 3, pp. 339-353, 1936.

The authors deal with the experimental study of the initial motion of seismographs caused by motions of short duration. An Ishimoto acceleration seismograph and Hagiwara velocity and displacement seismographs were used for the shaking-table experiment. The instrumental constants were determined, as far as possible, by static as well as dynamic methods. The results are summarized in a table. The transient motion of seismographs caused by certain types of somewhat irregular motions were studied experimentally, and the applicability of the simple method of reduction of the first ground impulsion described in part 1 (see abstract 3711) was verified. The applicability of the usual equation of motion was also proved, even for the start of motion of the pendulum with air damping so powerful that the damping constant $h$ was 7.99. The experimental arrangement of the shaking table and the connection between the motor and shaking table are 
shown in figures. Diagrams are given showing a comparison of the motion of the shaking table with those of displacement, velocity, and acceleration seismographs.-W. $A$.

3713. Kaye, M. K., Reconnaissance geology in State of Anzoategui, Venezuela, South America: Am. Assoc. Petroleum Geologists Bull., vol. 2, no. 2, pp. 233-245, 1937.

After a brief discussion on the general stratigraphy of the State of Anzoategui, a reconstruction of geologic events in the Anzoategui geosynclinal basin is attempted. Tentative conclusions are drawn from heavy-mineral work and are incorporated in the argument of geologic history. Suppositions as to the present shape and present sedimentation of the geosyncline are then drawn from the results and interpretations of seismic work with which the writer was associated. Finally, field practice in seismometry is briefly discussed.-A uthor's abstract.

3714. Kirillov, F. A., and Puchkov, S. V., Propagation of ground oscillations produced by impulsive forces [in Russian]: Acad. sci. U. R. S. S., Inst. séismol., Pub. 59, 20 pp., 1935.

Impulsive forces were produced by $(a)$ driving piles into the ground; and $(b)$ the work of a steam hammer. The following general conclusions are stated:

The energy producing the vibration of the ground consists of about 3.3 percent of the whole kinetic energy developed by the source. Amplitudes and acceleration of oscillations decrease rapidly with the distance, especially close to the source. The coefficient of damping of oscillations is greater in the vertical than in the horizontal plane. With the increasing depth of the driven pile, the amplitude of the oscillations decreases, following the hyperbolic law $B \mathrm{n} h h^{2}=$ constant $\left(h_{\mathrm{n}}=\right.$ depth of the driven pile and $B_{\mathrm{n}}$ the amplitude corresponding to the depth). By increasing the kinetic energy of the stroke the increase of the amplitude of oscillations varies as the square root of the height of the fall of the hammer. The periods of the horizontal oscillations are greater than the periods of the vertical oscillations. $-W . A$.

3715. Lynch, J. J., Modern seismology and some of its problems: Rev. Scientifle Instruments, vol. 7, no. 6, pp. 229-232, 1936.

Gives the elementary principle of the seismograph and a brief description of the Wood Anderson torsion seismograph and the Benioff vertical seismograph. The question, "How far below the surface does the earthquake shock occur?" and the possibility of determining the depth of the focus by the time intervals between the $P$ wave and the $\mathrm{pP}$ wave are discussed. In this way it has been found that some quakes have their origin at a depth of as much as 500 miles. An earthquake has usually been considered as caused by a fracture in the earth's crust. But as the crust is estimated to be from 10 to 40 miles thick and is supposed to be underlain by a region of flow, two possible explanatious arise for the deep-seated quakes: (1) they are caused by fractures occurring at much greater depths than was formerly thought possible; (2) they are produced by some other cause than fractures. The second suggested cause is taken from experimental thermodynamics-namely, that a deep-focus earthquake may be caused by the explosion resulting from a change of state occurring in some substances under the enormous pressure that exists hundreds of miles 
below the earth's surface. Therefore, the cause of earthquakes remains still an open question. The application of the data produced by seismology to seismic methods of prospecting and to the construction of buildings is briefly mentioned.- $W: A$.

8716. Martin, H., Einschwingvorgänge und ihre Bedeutung bei der Aufzeichnung von stossähnlichen Erschütterungen [Onset phenomena and their importance in the recording of shocklike oscillations] : Reichsanstalt für Erdbebenforschung in Jena Veröff, 26, Leipzig, 1935.

An attempt is made to give a comprehensive picture of the onset phenomena at seismometers and galvanometers.

1. Theoretical onset curves for sinusoidal excitations of any initial phase as recorded by galvanometers and seismometers are derived and explained by examples.

2. Various initial movements for the course of a shock are discussed, and the records obtained by seismographs are examined.

3. Theoretical considerations are confirmed by experiments with the aid of a new apparatus.

4. From the theoretical and experimental results important conclusions are derived concerning earthquake investigations and the fundamental requirements in the practice of oscillation measurements.Author's abstract, translated by W. A.

3717. McDermott, Eugene, Use of multiple seismometers: Petroleum Engineer, vol. 8, no. 5, pp. 135-137, Dallas, Tex., 1937.

The advantages of an arrangement of multiple seismometers (or detectors) as a means of discriminating between reflections and undesirable disturbances, such as ground-wave, wind, and traffic disturbances, are examined, and the conclusion is drawn that the use of eight seismometers in multiple will, under conditions generally encountered in the field, result in a factor of discrimination between reflections and undesirable waves amounting to at least 3 . Where the wave length of the ground wave may be determined, the factor may be larger than this. This could easily mean the difference between a usable and an unusable record. The distribution of the seismometers is shown in a series of figures, and the accomplishments are explained on a theoretical basis. $-W \cdot A$.

3718. Ramspeck, A., Wendepunkte in der Laufzeitkurve sinusförmiger Wellen [Turning points in the travel-time curre of sinusoidal waves] : Zeitschr. Geophysik, vol. 13, no. 1, pp. 1-8, Braunschweig, 1937.

The travel-time curve of sinusoidal waves produced in the ground is not a simple straight line when interference phenomena appear. In this case the travel-time curve has turning points at the interference maxima and minima. The apparent velocity at the turning points is determined from the velocity of propagation and from the amplitude of single waves.-Author's abstract, translated by W. A.

3719. Reich, H., Über die geologische Deutung ron seismischen Refraktionsmessungen [On the geologic interpretation of seismic refraction measurements] : Oel und Kohle, vol. 13, no. 3, pp. 53-59, Vienna, 1937.

After a brief outline of the principles of the seismic-refraction method the author gives the results of the refraction measurements made during a survey of Germany and concludes that the refraction method instead 
of the reflection method of seismic exploration must be used for the preliminary work, because the reflection method does not furnish information about the physical character of the reflecting layers or of the overlying layers. Besides, there is no better means of finding and delimiting a horst or a tectonic "high" than the refraction method. Tables showing the velocities of longitudinal waves are given for a number of areas. $-W$. $A$.

3720. Rieber, Frank, Applications of geosonograph to petroleum exploration: Petroleum Engineer, vol. 8, no. 5, pp. 140-142, Dallas, Tex:, 1937.

The application of the Rieber sonograph and photoelectric analyzer is described. The device has been developed for the particular purpose of conducting exploration in regions where the ordinary reflection seismograph yields confused records. It may, however, be employed in routine exploration also. The old style of visual record used in seismograph work was abandoned, and in its stead the earth vibrations were recorded as a sound track on photographic film. The special analyzing instrument was designed to separate and identify all individual waves in any crisscross pattern on the film. The performance of the analyzer is shown in a specific illustration, for a region in which the ordinary seismograph type of visual record gave no usable information.-W. A.

3721. Sezawa, Katsutada, and Kanai, Kiyoshi, Damping in seismic vibrations of a surface layer due to an obliquely incident disturbance: Tokyo Imp. Univ., Earthquake Research Inst., Bull., vol. 14, no. 3, pp. 354-359, 1936.

The calculations are restricted to the case of distortional waves with displacement oriented horizontally in order to avoid complexities in the problem. Formulas are derived.-W. A.

3722. Sezawa, Katsutada, and Kanai, Kiyoshi, The effect of stiffness of floors on the horizontal vibrations of a framed structure: Tokyo Imp. Univ., Earthquake Research Inst., Bull. vol. 14, no. 3, pp. 366-376, 1936.

To see if in their previous investigations on energy dissipation in the seismic vibrations of framed structures the assumption that the floors were extremely rigid and extremely flexible was reasonable, the authors give a mathematical solution for a multispanned framed structure by using their dynamical method as well as by the slope-deflection method, showing that whichever way the problem is solved the result would be the same. Empirical formulas for the principal vibration frequencies for any number of stories are derived.-W. $A$.

3723. Sezawa, Katsutada, and Kanai, Kiyoshi, Energy dissipation in seismic vibrations of actual buildings predicted by means of an improved theory: Tokyo Imp. Univ., Earthquake Research Inst. Bull., vol. 14, no. 3 , pp. $377-386,1936$.

In a previous paper (Improved theory of energy dissipation in seismic vibrations of a structure: Geophys. Abstracts 87, no. 3360) the authors obtained improved formulas for the energy dissipation in seismic vibrations of a structure as the result of more accurate treatment of the points that had been somewhat approximate in the original problem. In this paper a mathematical discussion is given for a 3-storied and a 7-storied structure.-W.A. 
3724. Sezawa, Katsutada, The effect of differences in the media on the distribution of displacements in a seismic wave front: Tokyo Imp. Univ., Earthquake Research Inst. Bull., vol. 14, no. 4, pp. 506-513, 1936.

The distribution of the initial motion--that is, the distribution of the displacements in a wave front at different radial distancesis affected by the nature of the medium through which the waves are transmitted. Unless both the density and the elasticity of the seismic region are about the same for different earthquakes, the study of the mechanism of a seismic origin from the data of the initial motion would be impossible, even if the frequency of the initial motion were specified. Sezawa gives in as convenient a form as possible formulas for (1) pure distortional waves generated from a spherical origin, and (2) both dilatational and distortional waves radiated. from a spherical origin.-W. $A$.

3725. Sezawa, Katsutada, and Kanai, Kiyoshi, Energy dissipation in seismic vibrations of an S-storied structure: Tokyo Imp. Univ., Earthquake. Research Inst. Bull., vol. 14, no. 514-524, 1936.

A mathematical theory of the problem is developed and applied to the 8-storied Marumouti Building in Tokyo. The calculated results of the important elements are shown in a table that may be used in almost any theoretical treatment of horizontal vibration of the -structure under consideration.-W. $A$.

3726. Sezawa, Katsutada; and Kanai, Kiyoshi, On the seismic vibrations of a gozyunoto [pagoda]: Tokyo Imp. Univ., Earthquake Research Inst. Bull., vol. 14, no. 4, pp. 525-532, 1936.

From the present investigation it has been ascertained that the gozyunoto (5-storied pagada) is earthqualke-proof solely because of the fact that the effective height of the elastic part of its structure is extremely small, the induced stress due to the ground vibration being consequently very small. The relatively large stress under resonance condition is still restricted to a certain limiting value due to the fairly large dissipation of the vibrational energy into the ground. The central post, even in the hanging state, has no effect in preventing large vibrations, although it rather gives rise to an additional resonance condition of the tower. Nevertheless, in order to make the central post effective on the vibration damping of the tower, it is rather advisable to insert some viscous damper between the central post and the tower body, its full character being now investigated.Authors' abstract.

3727. Shnirmann, G. L., Electrical methods of graduating electrodynamic seismographs and oscillographs [in Russian]: Acad. sci. U. R. S. S., Inst. séismol., Pub. 55, 22 pp., 1935.

Gives a method of determining the constants of electrical seismographs and oscillographs of electrodynamic type, similar to Galitzin's seismograph with galvanometric registration. The general theory of the question and the graduation of the instruments in the laboratory and in the field are discussed mathematically. $-W . A$.

3728. Shnirmann, G. I., Condenser seismograph [in Russian] : Acad. sci. U. R. S. S., Inst. séismol., Pub. 56, 14 pp., 1935.

Discusses preliminary investigations and experiments on the development of an apparatus for the transformation of mechanical vibra- 
tions into electrical vibrations, and the oscillographic recording of these oscillations photographically. A mathematical discussion is given, and the operation of the experimental apparatus is explained by a schematic design. The conclusion states that the condenser method of registering mechanical vibrations and deformations makes it possible to record long periodic processes as well as slow aperiodic processes.W. A.

3729. Shnirmann, G. L., Electromagnetic seismograph [in Russian] : Acad. sci. U. R. S. S., Inst. séismol., Pub. 67, pp. 9-14, 1935.

Describes an electromagnetic seismograph by which the energy of the mechanical oscillations can be transferred into electric current. The main features of the apparatus consist of a differential magnetic bridge provided with an iron magneto-wire and an inductance in the zero branch line. The system is connected with the inert mass and the support, and relative displacement of the support changes the magnetic resistance in the main branches of the bridge. A schematic diagram accompanies the explanation. $-W$. A.

3730. Sokoloff, P. T., and Skriabin, V. I., Experimental and theoretical investigations on dispersion and absorption of elastic waves: Gerlands Beitr. Geophysik, vol. 49, no. 1/2, pp. 165-198, Leipzig, 1937.

An explanation of the elastic properties of a group of rocks is based on experimental and theoretical investigations of these rocks as to the dispersion, absorption, reflection, and refraction of elastic waves. A mathematical discussion is given of (1) the solution of special problems of the theory of elasticity and the definition of the constants of elastic hysteresis; (2) the dispersion and absorption of elastic waves; and (3) the reflection and refraction of the elastic waves in the absorbing and dispersing medium.-W. $A$.

3731. Stoneley, R., Surface-waves associated with the $20^{\circ}$ discontinuity: Royal Astron. Soc. Monthly Notices, Geophys. Suppl., vol. 4, no. 1, pp. 39-43, London, 1937.

Although the surface layers extend to less than one-tenth the depth of the discontinuity, the material above the discontinuity may in a general way be regarded as a surface layer; and accordingly it would be expected that surface waves of the Love type and of very long wave length should be propagated, if suitably excited; and that Rayleigh waves of long period should be modified in much the same way as the waves of moderate periods are altered by the presence of the surface layers. Ultimately, too, the existence of such waves would be a check on the depth and amount of the jump in density and elastic properties. Tables of values of $k T$ for a series of values of $c / \beta$ and the group velocity $C$ are given. $-W$. $A$.

3732. Stoneley, R., Love waves in a triple surface layer: Royal Astron. Soc. Monthly Notices, Geophys. Suppl., vol. 4, no. 1, pp. 43-50, London, 1937.

The theory of the propagation of Love waves is worked out for a triple surface layer resting on uniform material. An outline is given of the method of proof that such waves can exist for the distributions of density and rigidity postulated, and it is shown that in certain circumstances waves with nodal planes may exist. A special application 
of the theory is made to the question of determining the thickness of the sedimentary layer of the continents when the densities, rigidities, and thicknesses of the granitic and intermediate layers are known, and likewise the densities and rigidities of the sedimentary layer and of the ultrabasic material that lies beneath the continents. A range of likely values of the rigidity of the sedimentary layer gives, for the most part, a thickness round about 3 kilometers.-Author's abstract.

3733. Ulrich, F. P., Progress report for 1935 of the California seismological program of the United States Coast and Geodetic Survey: Seismol. Soc. America Bull., vol. 26, no. 3, pp. 215-228, 1936.

The main progress concerns

(1) Instrumental improvements: New recording devices to eliminate a slight nneven rotation of the receiving drum and low-magnification attachments were installed in accelerographs; the Weed seismograph has been improved by substituting pendulum starters for the contact starters.

(2) Tiltmeter work: Four tiltmeters have been kept in operation with the object of obtaining satisfactory continuous records.

(3) Vibration work: Approximately 200 observations of building vibrations, special vibration observations on a large dam at the time of a nearby explosion, and other vibration observations were made.

Little success in determining dominant ground periods was obtained.

(4) Shaking machine work was done in five buildings, on three dams, one bridge, and three ground tests. Reports covering these observations are prepared.

A very thorough report was completed, under the supervision of $\mathbf{B}$. Gutenberg, on the dominant ground periods as measured on approximately 2,000 seismograms. Strong-motion records were interpreted, and special attention was given to the response of instruments and buildings to ground motion. New shaking tables bave been constructed and tested for use in checking field instruments. $-W$. $A$.

3734. Urren, L. C., New method of seismic survey affords more information: Oil and Gas Jour., vol. 35, no. 43, pp. 52-55, Tulsa, Okla., 1937.

The Rieber sonograph differs from the reflection seismograph not only in the character and appearance of the original records made in the field but also in the method of analyzing and interpreting these records. A device termed a "receptor" is used, in which a piezoelectric quartz crystal transforms a selected part of the earth vibrations into electric wares. These waves are then passed through a specially controlled amplifier and finally recorded on a strip of motion. picture film. After the development, the film passes through a special apparatus termed the "sonograph analyzer", which "reads" the film and determines what waves may be present. The use of this sonograph analyzer, by which the operator identifies the data from this strip and converts them into subsurface information, is explained. It is claimed that this method is capable of providing specific information near faults and under structural conditions where earlier methods were unable to avoid confused wave patterns. Another advantage of the method is the almost automatic and mechanical character of the recording and analyzing process.-W. $A$. 


\section{ELECTRICAL METHODS}

3735. Arnold, G., Fehlerquellen bei der Messung von Erdströmen in kurzen Leitungen, untersucht im Taunus-Observatorium [Sources of error in measuring earth-currents in short lines, as observed in the Taunus Observatory] : Gerlands Beitr. Geophysik, vol. 49, no. 1/2, pp. 140-164, Leipzig, 1937.

The possibility of making earth-current measurements in short lines is examined. It is found that even under the most ideal conditions of the ground and electrodes there occur contact potential differences, the fluctuations of which, in the case of compensated equilibrium potential, exceed the daily variations of the earth current. Stray currents are discussed and it is shown that owing to the polarization of the electrodes the absolute value of the existing potential differences cannot be measured. Therefore, earth currents and their natural and artificial disturbances cannot be measured in short lines accuratel. with the electrode materials used.-Author's abstract, translated by W. A.

3736. Barbey, O., Die Anwendung der elektrischen Bohrlochuntersuchungsmethoden [Application of electrical methods for bore-hole investigations] : Bohrtechniker Zeitung, vol. 55, no. 3, pp. 57-58, Vienna, 1937.

Gives a brief description of electrical methods used for electrical coring, temperature measurements, measurements of the resistance of the mud, inclination of the hole, and the perforation of casing inserted in a hole. $-W . A$.

3737. Dostovalov, B. N., Generator with directed radiation for prospecting by the inductive method [in Russian]: Materials of Central Geol. and Prosp. Inst., Geophysics, no. 2, pp. 42-54, Leningrad, 1936.

After a brief description of the fundamental basis of the inductive method, the pernicious action of the primary field at the reception point is discussed, and the principles and physical features of the composition of the magnetic fields in the coil and vertical antennas for obtaining measurements in the form of a cardioid are described. As the necessary direction of the radiation had not been attained by the combination of coil antennas, experiments were made with a cardioid generator, the main difficulty being the problem of obtaining a thoroughly portable generator adapted for the high frequencies used in the inductive method. Two schemes, one simple and the other more complex, for the installation of and experiments with cardioid receivers are discussed. Owing to the necessity of observing portability, the application of the simple scheme was rejected and the experiments were carried out with the complex scheme, their contour behavior having been calculated by $\mathrm{A}$. Petrovsky. According to the scheme a transmitter was designed, constructed, and tested first over a grounded wire and after this in natural conditions on the experimental field. The tests, although not very numerous, furnished good results under conditions where the normal application of the inductive method was not able to detect anything. Some practical suggestions on the experimental work with the cardioid generator are given in the conclusion of the paper.-Author's abstract. 
3738. Electrical logging and its applications in modern petroleum prospecting [editorial]: Petroleum Engineer, vol. 8, no. 5, pp. 155-159, Dallas, Tex., 1937.

The following electrical logging methods are described: (1) The Schlumberger method consists in measuring the electrical properties of formations penetrated by a drill hole (resistivity and porosity survey).

(2) Temperature surveys, another phase of the Schlumberger method, can be advantageously used for (a) locating gas- or oil-bearing strata in open holes; $(b)$ locating water-bearing formations discharging fluid into a well; $(c)$ locating the top of the cement behind the casing; and (d) logging the different formations behind the casing. (3) The geoanalyzer method of electrical logging provides two curves (permeability curve and saturation curve) from which interpretations are made and subsurface data procured. These curves are photographed on a strip of film which, developed and fixed, is ready for use within a few minutes after the logging run is completed. The entire operation is automatic. (4) The distinctive feature claimed for the stratagraph method is its ability to record electrically at the surface the electrochemical characteristics of the strata lying behind the casing in the hole. By using certain electrolytes in the well, records are obtained by running electrodes into the liquids in the casing. In petroleum prospecting this method is used for correlating the strata in fields where little is known of the substructure.-W. $A$.

3739. Fedukovich, V., Electrometric prospecting in the Ukrainian S. S. R. [in Ukrainian] : Jour. Geology, vol. 3, no. 3/4, pp. \$3-11.0, Kiev, 1937.

A general review of electrometric prospecting in the Ukraine up to 1935 is given. The method of equipotential lines was used in prospecting for manganiferous iron ores in the Khashchevatski region. Anomalies were determined. Prospecting for ores in the Krivoi Rog was carried out by resistivity methods. The following advantages of electrical prospecting were demonstrated: (1) The thickness of alluvium could be established fairly well; (2) in profiling, the strikes of ore-bearing layers were traced; and (3) ore deposits could be determined by electro-profiles, although not always very clearly. Resistivities of a series of rocks in this area are shown in a table.

In the region of the Nagolny Ridge special interest was attached to prospecting for complex sulphide ores which occur here in quart\%ankerite veins. Well-defined indications of the presence of quartz veins were obtained by electric profiling, using immovable power electrodes. It was also observed that Carboniferous limestones and sandstones could be traced in the schist masses.

Electroprofiling, electroboring, and electrical coring of bore holes were applied for exploring coals in the Carboniferous rocks of the Don Basin. The following conclusions are given: (1) The recognition of tectonic disturbances beneath the alluvium and the determination of their strikes was possible; (2) it was also possible to trace the distribution of the Carboniferous system beneath the younger deposits and to determine the thickness of the superincumbent rocks. $-W . A$. 
3740. Fritsch, Volker, Beiträge zur Funkgeologie-Einiges ïber die Ausbreitung Hertzscher Felder in Gebirgen [Contributions to radiogeologySome remarks on the propagation of Hertzian fields in mountains]: Beitr. angew. Geophysik, vol. 6, no. 3, pp. 277-306, Leipzig, 1937.

The receiving set is placed in a cavity while the sender is above ground. The electromagnetic waves travel to the receiver partly through the rock, partly through fissures, and partly along the surface. The scientific and practical part of the problem is explained in the first section. In order to determine the damping of the field on its way through the rock one must know the value of the coefficient of absorption. The order of magnitude of this coefficient, as found theoretically by present methods, is quite different from that found by experiment. The author examines, in the succeeding section, the composition and electrical properties of geologic conductors and media, reviewing the literature and adding experiments of his own. Having thus defined the geologic structures electrically, the author applies to them the general principles of radiophysics. General equations for the propagation process are deduced. These theoretical results are checked by comparison with experience. It is found that the theory of propagation, correctly applied, is capable of giving a qualitatively correct representation. Quantitative conclusions cannot yet be drawn, because the electrical structure of the geologic conductor is rather complicated and not yet sufficiently known.

Practical applications of the results are discussed with reference, to mine radio and to wireless prospecting. Mine radio has to serve for wireless communication between the mine and places above ground, when the ordinary mine telegraph is out of order. Wireless prospecting serves to ascertain the position and the nature of a deposit by recording the alterations of an electromagnetic field caused by the presence of that deposit-that is, by measuring its absorption. The author hopes to contribute, by this paper, to the treatment of this problem, while not claiming to give a complete solution.-Author's abstract, translated by W. A.

3741. Fritsch, Volker, Mitteilung über die Funkversuche im Sommer 1936 auf der Donau zwischen Passau und Russe [On radio tests on the Danube between Passau and Russe in the summer of 1936] : Hochfrequenztechnik und Elektroakustik, vol. 49, no. 3, pp. 94-98, Leipzig, 1937.

Gives the results of tests concerning the conditions of radio reception carried out on a 10-meter band over a section of the Danube approximately 1,700 kilometers long. The following conclusions are drawn:

1. The wave diagram is considerably distorted, not only by the course of the river on the surface but also by underground watercourses.

2. It is found that, even in valleys with a very winding course, radio communication on the 10-meter 'band is possible.

3. A strong absorbing influence in the cataract section, where the river crosses the Carpathian Mountains, was found from the tests made on the lower Danube. The absorption is probably due to the existence of extensive ore deposits not yet discovered in the mountains along the river.

4. It was also observed that no message could be recorded with sufficient certainty in the cataract region of the lower Danube during the day. $-W$. A. 
3742. Golovtzyn, V. N., On the possibility of application of the electrometric method for studying karst phenomena [in Russian] : Acad. sci. U.R. S. S., Inst. séismol., Pub. 52, 65 pp., 1935.

In studying karst phenomena the following questions are to be considered :

1. Is there one uninterrupted water horizon, and how can its lower border be traced?

2. Are there separate caverns of karst water, or are they connected with one another; what is their distribution?

3 . What is the depth of the karst, and are the caverns dry or filled with water?

4. Are there ground waters at the horizons of the caverns or at depths different from those of the caverns, and what is the direction of the flow?

5. What is the velocity of the flow?

6. What connection exists between the display of the karst topography on the surface and the subterranean karst waters and dry karst caverns?

Mathematical foundations for the application of electrical methods are given, and experimental laboratory work on models is described. Necessary conditions for the possible solution of the questions under consideration are discussed. It is concluded that the electrical investigation of karst phenomena may be successful if conducted with a geologic knowledge of the area and that interpretations of individual results can be made in the field. $-W . A$.

3743. Horvath, Sepp, The genphysical methods of the Electrical Prospecting Co. of Sweden used in the Aerial, Geological, and Geophysical Survey of Northern Australia: Aerial, Geological, and Geophysical Survey of Northern Australia Rept. 3, 23 pp., Queensland, June 1936.

General principles of the self-potential method, potential method, and electro-magnetic methods of prospecting and the instruments used in the geophysical survey are described. A brief description of the magnetic method is added.-W. $A$.

3744. Hummel, J. N., and Rïlke, O., Der Einfluss der Dickspiilung auf den scheinbaren spezifischen Widerstand [Influence of mud filling of bore holes on the apparent specific resistance]: Beitr. angew. Geophysik, vol. 6 , no. 3, pp. 265-270, Leipzig, 1937.

As a rule mud fillings of bore holes have a specific resistance different from that of the rock. It is found that the apparent specific resistance of the filling differs considerably from that of the rock for small distances between the electrodes in extensive strata, but for a distance about 10 times the diameter of the bore hole the difference is negligible.Authors' abstract, translated by W. A.

3745. Jakosky, J. J., and Wilson, C. H., Prospecting for oil structures by electrical methods : Petroleum Engineer, vol. 8, no. 5, pp. 143-148, Dallas, Tex., 1937.

Describe a new electrical method for oil exploration and discuss briefly the results recently obtained in field work. Part A, dealing with (1) the development history; (2) factors influencing the flow of electric current through rocks; (3) the presentation of field data; (4) the correlation of field data; (5) systems of field measurement; and (6) fault traverses, is written by Jakosky; and part B, dealing with the results obtained in San Joaquin Valley, Calif., and Karnes and Goliad 
Counties, southern Texas, by Wilson. A series of figures gives (1) a . structural profile of San Joaquin Valley, showing geophysical correlation and the close relationship to wells subsequently drilled in the area;

(2) fault locations and subsurface structure contours determined by an electrical geophysical survey; (3) the results of electrical work, showing subsurface contours on the base of the salt, in Goliad County, Tex.; and (4) part of a structural profile determined by electrical methods. The electrical work was employed to determine the existence of a possible structural high along the line of the traverse. No such structure was indicated, and subsequent drilling not only confirmed this fact but also determined the base of the salt at a depth within 20 feet of that indicated electrically.-W. $A$.

3746. Löwy, H., Der Fundamentalsatz der angewandten Geophysik [The fundamental principle of applied geophysics] : Beitr. angew. Geophysik, vol. 6, no. 3, pp. 271-276, Leipzig, 1937.

The problem of interpreting different geophysical methods is discussed, and the necessity of a knowledge of the regional geology in interpreting the data obtained from geophysical prospecting is stressed. It is shown that in arid regions direct indications of the presence of ore, oil, and water can be provided by electromagnetic methods. In humid regions better results may be obtained by using resistivity methods.W. A.

3747. Mikhailov, I. G., The phase effect in the inductive method of geophysical prospecting [in Russian]: Materials of the Central Geol. and Prosp. Inst., Geophysics, no. 2, pp. 19-37, Leningrad, 1936.

Gives a brief account of the inductive method in its recent development with mathematical calculations based on the theory rof connected circuits, and expressions for the phase displacement between the magnetic fields from the currents in the circuit generating the frequency and the circuit with the induced current. The absorption of the magnetic field by the earth and the necessity of taking into account effects of elliptical polarization, are mentioned as difficulties encountered in the practical application of the phase method. $-W . A$.

3748. Mikhailov, I. G., Reduction of the primary field by means of a screened coil [in Russian]: Materials of the Central Geol. and Prosp. Inst., Geophysics, no. 2, pp. 37-42, Leningrad, 1936.

To reduce the ratio of the primary and secondary magnetic fields $\frac{H_{1}}{H_{2}}$ in the inductive method the author compensates the horizontal component of the magnetic field at the reception point, using for this purpose the action of a coil tuned on the frequency of the transmitter and placed during the measurements in front of the receiving coil. The plane of the tuned coil is vertical and passes through the radiation and reception points. The dependence of the compensation on the geometrical distribution of coils, their dimensions, and electrical parameters is mentioned. The results of measurements over models confirmed the general theoretical considerations and showed the advantages of applying a screened coil as compared with the usual inductive method, especially for small veins and lenses.-Author's abstract, translated by W. A. 
3749. Mikhailov, I. G., Electromagnetic field of an inclined frame [in Russian] : Materials of the Central Geol. and Prosp. Inst., Geophysics, no. 2, pp. 54-62, Leningrad, 1936.

In using the induction method of geophysical prospecting, it is of great importance to determine the characteristics of the electromagnetic field of the generating frame when inclined to the surface of the earth. The results of the mathematical calculations of the field of the inclined frame are given in formulas, tables, and graphs. $-W . A$.

3750. Pylaev, A. M., Experiments with models by inductive methods [in Russian]: Materials of the Central Geol. and Prosp. Inst., Geophysics, no. 2, pp. 4-19, Leningrad, 1936.

Describes the results of experiments with a model having the form of a flat conductive metallic net 5 meters long and 1 meter wide, enclosed in a wooden frame. The experimental installation consisted of a transmitter and a receiver. The normal distribution of the induced currents-that is, the concentration of the direct and reverse current in the upper and lower edges of the model respectively-was confirmed. Another set of experiments had previously shown the expediency of applying theoretical curves of standard graphs of depth to give the depths of the electrical axis of the anomaly with sufficient precision. The experiments on the determination of the optimum distance between the transmitter and receiver during the measurements of profiles had shown that the method generally adopted of taking the greatest possible distance was incorrect; the necessity of choosing this distance experimentally in each case was proved. Tests with an inclined model did not confirm the results expected on the basis of field observations and even showed a very slight inverse effect. In further experiments, the effect as obtained in practice was evoked artificially. It is supposed that the discordance is caused by the nonconductivity of the medium enclosing the model. The observations over the horizontal model did not give any anomaly if the coil was centered, but if the coil was placed asymmetrically, the anomaly was observed distinctly.-Author's abstract, translated by W. A.

3751. Shakhnes, K. A., Application of electrical prospecting to hydrology [in Russian] : Razvedka Nedr, vol. 7, no. 3, pp. 19-24, Moscow, 1937.

Discusses electrical prospecting for water by resistivity methods and the method of spontaneous polarization. Three practical cases are examined. (1) The depth of ground water was indirectly determined by establishing the depth of a clay layer of great magnitude. (2) The geologic section consisted of a constant alternation of pebbles, argillaceous soil, and clay of various and comparatively small magnitudes. Maps of equal resistances for the depths of about 3,5, 10, 20, and 50 meters were constructed from which the conclusions on the waterbearing beds and on the mineralization of the water were made. (3) Investigations were made in the valley of the Malyi Kizil River in the region of Magnitogorsk. The geologic section consisted here of carbonaceous limestones, limestones, tuffs, and more recent formations of eluvium and alluvium. The existence of the old river bed was determined by both methods. The electrical profiles are shown 
in figures. The general conclusion is drawn that problems of prospecting for water may be satisfactorily solved by electrical methods.W. $A$.

3752. Shaw, S. H., Geo-electrical measurements in drill holes: Mining Mag., vol. 56, no. 1, pp. 17-23, London, 1937.

Methods are described for logging drill holes by electrical resistivity measurements. The results in two shallow bore holes in Birming: ham are given. The two holes, the Laundry hole and the Oil Department hole, about 500 feet apart, were investigated; and the resistivity curves for both the holes are given in a figure. A complete and detailed geologic record obtained from the Laundry hole cores is shown in a table. Comparison of the resistivity curve from the Laundry hole with the drill $\log$ shows a satisfactory agreement between changes in rocks and changes in resistivity. The value of the use of resistivity" methods in drill holes for correlation, as well as for obtaining important information in connection with measurements of surface resistivity is recognized. The resistivities in formations determined in drill holes are likely to be more accurate, because the resistivity of the surface soil does not enter into them and does not modify them in any way. $-W$. $A$.

3753. Soloviev, A. V., Tests of geophysical prospecting for pegmatite veins in the region of the Biriuzinsk muscovite deposits [in Russian]: Razvedka Nedr, vol. 7, no. 3, pp. 9-12, Moscow, 1937.

From tests made in Biriuzinsk the following conclusions are drawn: Electrical prospecting should be applied on a large scale in carrying on prospecting for muscovite deposits in pegmatite veins, but efficiency cannot be attained unless the geophysical work is accompanied by mining. Every section designated for prospecting must first be studied geophysically. This will make it possible to eliminate sections that are unsuitable and to direct the mining work to points where pegmatite reins may be expected.-W. $A$.

3754. Barrow, W. L., Transmission of electromagnetic waves in hollow tubes of metal: Inst. Radio Engineers Proc., vol. 24, no. 10, pp. 1298-1329, New York, 1936.

Electromagnetic energy may be transmitted through the inside of hollow tubes' of metal, provided the frequency is greater than a certain critical value; this value is inversely proportional to the tube radius and to the dielectric coefficient for the tube interior. Calculations and measurements of the more important characteristics of this new kind of transmission system have been made, and the conditions for minimum attenuation obtained. Terminal devices for connecting a hollow pipe system to a biconductor system, and others, in the form of horns, for directly radiating radio waves, have been developed; these electromagnetic horns may also be fed with ordinary coaxial lines. Certain types of terminals act as sharply resonant hollow-tube elements. Several independent communication channels may be established within a single pipe line by utilizing distinct types of waves for each channel in a unique kind of multiplex operation. A section of a hollow tube may be used as a high-pass filter. Although presupposing adequate technique for the generation and utilization of the shortest radio waves, this new system possesses 
several features, among which are a minimum dielectric loss, substantially perfect shielding, and a simplicity of structure.-Author's summary.

3755. Carson, J. R., Mead, S. P., and Schelkunoff, S. A., Hyper-frequency wave guides-mathematical theory: Bell System Tech. Jour., vol. 15, no. 2, pp. 310-333, New York, April 1936.

Following a brief historical sketch, this paper deals with the mathematical theory of wave transmission in two novel kinds of cylindrical ware guides of circular cross section-namely, the hollow conductor and the dielectric wire. These transmission systems behave as high. pass filters with exceedingly high critical frequencies. The attenua tion and impedance characteristics of the hollow conductor, heretofore ignored as far as the writers are aware, are given especial attention. This investigation discloses the remarkable fact that there exists in this system one and only one type of wave, the attenuation of which decreases with increasing frequency, a characteristic which attaches to no other type of guided wave known to the writers.-Authors' abstract.

3756. Norton, K. A., The propagation of radio waves over the surface of the earth and in the upper atmọsphere: Inst. Radio Engineers Proc., vol. 24, no. 10, pp. 1367-1388, New York, 1936.

simple formulas and graphs are given which represent the groundwave field intensity at the surface of the earth as radiated from a short vertical antenna at the surface of the earth. The theory is compared to some experimental results reported by other investigators, to determine its range of application. The diffraction formula given is theoretically valid only at the lower frequencies; however, it was shown that sky waves are important both day and night and over land and sea at those distances where diffraction would otherwise cause a marked decrease in the received field intensity. The attenuation formula given for the short distances where diffraction may be neglected is theoretically valid for any frequency and set of ground constants; experimental data are given which show that the formula may be used even at the ultrahigh frequencies.-Author's summary.

3757. Southworth, G. C., Hyper-frequency wave guides; general considerations and experimental results: Bell System Technical Journal, vol. 15, no. 2, pp. 284-309, New York, April 1936.

A peculiar form of electrical propagation is described. It makes use of extremely high frequencies, even beyond those generally employed in radio. In some respects it resembles ordinary wire transmission, but unlike the latter there are no return conductors, at least of the usual kind. In this transmission electromagnetic waves are sent through guides made up either of an insulator alone or of an insulator surrounded by a conductor. In a special case this insulator may be air. There are at least four different types of waves or electrical configurations that may be propagated. One of them is such that theory indicates that its attenuation through a hollow conductor continuously decreases with increase of frequency. Although the paper deals largely with the nature of this transmission, some of the fundamental pieces of apparatus used in experimental work are described. They include generators, receivers, and wave meters.-Author's abstract. 


\section{RADIOACTIVE METHODS}

3758. Evans, R. D., Apparatus for the determination of minute quantities of radium, radon, and thoron in solids, liquids, and gases: Rer. Scientific Instruments, vol. 6, no. 4, pp. 99-112, 1936.

The radium content of ordinary materials is determined by removIng and measuring the radon which is in equilibrium with the radium.

I. Generalization of the direct fusion furnace method now permits the rapid and complete deemanation of any solid by direct boiling at $2,000^{\circ} \mathrm{C}$.

II. Improved boiling apparatus for the removal of radon from liquids avoids loss of traces of radon by absorption.

III. Gaseous samples, at atmospheric pressure, may be examined directly for radon.

IV. Double ionization chambers, coupled to a high-sensitivity string electrometer, permit observations on very feeble sources. Statistical fluctuations in the emission of contaminating alpha rays from the ionization chamber walls impose a natural observational limit of $7.2 \times 10^{-14}(n)^{-1 / 2}$ curies of radon, when the ionization currents are observed for $n$ hours.

V. Photographic recording of the ionization current, with hourly automatic recalibration of the electrometer at three arbitrary potentials, makes possible long runs and higher precision, particularly for weak sources.

VI. Induction, null-induction, and ionization methods for the measurement of the electrostatic capacity of ionization chamber systems are described.

VII. Caution is given against a spurious ionization, of unknown origin, occasionally observed in connection with radon tests.

VIII. The flow method for the measurement of thoron is shown to be more applicable to liquid samples than to solids. Under normal operating conditions the emanating power of liquid samples is about 0.6.

IX. Mean values of the radium content of certain classes of rocks, sea waters, and organisms are given.-Author's abstract.

3759. Kurbatov, L. M., On the radioactivity of bottom sediments: Am. Jour. Sci., 5th ser., vol. 33, no. 194, pp. 147-153, 1937.

Samples of ferromanganese formations from nine seas and lakes of the U. S. S. R. are investigated and compared with two manganese samples from the Pacific. The method of investigation is briefly described, and the results showing the radioactivity of the formation are given in two tables. The conclusion is drawn that the concentration of radium in ferromanganese formations is evidently the result of the precipitation of radium, together with colloidal forms of iron, from the water as the result of various chemical or biochemical processes. $-W$. $A$.

3760. Lane, A. C., Rating the geologic clock: Reprint from 16th Internat. Geol Cong. Rept., pp. 145-167, 1936.

Many methods are mentioned that have been employed to estimate parts of geologic time. All must depend on using a present rate of activity of some process and extrapolating into past time. Calculations based on present rates may be affected by present abnormalities of these rates. The processes may be periodic, progressive in one direction, or in regularly recurring paroxysms. The most reliable 
methods seem to be those that depend on the disintegration of atoms, and the results of these check in a broad way with the times indicated by cyclic banding, which may be ascribed to periodic fluctuations, either yearly or of longer periods, such as the processional cycle, and give us a clue to the rate of progressive accumulation of strata. The ratio of lead to uranium and thorium in the oldest minerals indicates that they are not less than 1,300 million years old. By the ratio of radium $\mathrm{G}\left(\mathrm{Pb}_{200}\right)$ to uranium the age of the Upper Cambrian can be fixed as about 420 million years, the Taconic uplift as about 350 , and the Caledonian granite invasion as about 280 , and it thus seems probable that every 60 or 70 million years or so the crust of the earth yields to some accumulated stress.-A uthor's abstract.

3761. Mouzon, J. C., Geiger Müller counters : Rer. Scientific Instruments, vol. 7, pp. 467-470, December 1936.

A simple amplifier and recorder circuit for discriminating between partial and total coinciciences of Geiger-Müller counters is described.Author's abstract.

\section{GEOTHERMAL METHODS}

3762. Kraskorski, S. A., On the thermal conditions of salt domes [in Russian] : Razvedka Nedr, vol. 7, no. 3, pp. 15-1S, Moscow, 1937.

This study is based on the data obtained in foreign countries, especially in the United States, as no suflicient information on the distribution of depth temperatures is available in the U. S. S. R. The few measurements made in the latter country vary to such a degree that no conclusions can be drawn from them. Thus in Piatigorsk (Caucasus) the geothermal gradient was found to be equal to $1.5 \mathrm{~m} /{ }^{\circ} \mathrm{C}$, while in the Krivoy $R \circ g$ this gradient amounted to $112.5 \mathrm{~m} /{ }^{\circ} \mathrm{C}$. The thermal anomalies observed in coal-bearing regions, regions of ore deposits, oil fields, and salt domes are studied, and the explanations of their causes given by Werner, Hawtof, Van Orstrand, and others are discussed.-W. A.

3763. Kraskorski, S., Geothermal measurements in the Stalin region, Donetz Basin [in Russian]: United Geol. and Prosp. Service of U. S. S. R., Mineral Resources, no. 1, pp. 29-39, Leningrad, 1933.

The work consisted of (1) geothermal observations in deep bore holes; (2) determination of geothermal gradients in holes drilled in prospecting for coal; and (3) testing field equipment devised by the geothermal section of the Central Prospecting Institute. Measurements were made with maximum centigrade thermometers enclosed in a steel case, attached to a steel cable, and lowered by means of a special reel. The time required for taking the temperature of the surrounding medium was determined in the laboratory to be 20 minutes, but 40 minutes was allowed for temperature tests in the bore holes. The distribution of temperature was studied in five bore holes having depths ranging from 383 to 912 meters. After the completion of a measurement the bore hole was washed during 8 hours with water having a temperature of about $+5^{\circ} \mathrm{C}$. After this the measurement was repeated. A mean temperature of $0.39^{\circ} \mathrm{C}$. was established in the difference between the temperatures before and after the washing. Changes of temperatures with depth are shown in curves. All the results of the measurements are shown in five tables.-W. $\boldsymbol{A}$. 


\section{UNCLASSIFIED METHODS}

3764. Antonov, P. L., On the fundamental equations of gas survey [in Russian] : Neftianoe Khoziaistvo, vol. 18, no. 1, pp. 29-32, Moscow, 1937.

The mathematical interpretation of gas survers proposed by $\mathbf{V}$. A. Sokolov is criticized, and the conclusions are given that (1) formulas proposed by Sokolov are not original but only a simplification of formulas proposed by Antonov; (2) the simplification is not justified, because an incorrect presentation of the character of the emanation of hydrocarbon gases from the productive layers is introduced; (3) the method of contouring (and the determination of the depths of deposits) by using Sokolov's formulas produced distorted results in a series of cases.

The application of Sokolov's formulas for the further development of the method of mathematical interpretation is therefore considered inconsistent. $-W . A$.

3765. Blau, L. W., The interpretation of geophysical data: Oil Weekly, vol. S5, no. 3, pp. 23-29, Houston, Tex., 1937.

This is a part of the great problem-the problem of geophysics and the problem of all prospecting and geology-the problem of interpretation. 'The solution is not in sight, but it behooves the geologist to work earnestly and sympathetically with the physicist, to the end that their results may be translated, as exactly as possible, into structure maps, into the language that the oil froducer and executive have already learned to read.-Abstract by $E$. DeGolyer.

3766. Clay, J., Hooft, C. G., Day, L. J. L., and Wiersma, J. T., Intensity of cosmic rays in the earth's crust: Physica, vol. 4, pp. 121-137, February 1937.

An experimental test of the super-nova hypothesis was made by measurements in the coal mine at Kerkrade at depths of $46,102,143$, and 260 meters. The systematic rariations, calculated by Zanstra, proved to be of the same order as the unsystematic variations found. A variation of 0.04 percent of the hour ionization charge at sea level could be measured. At 200 and 260 meters the intensity of rays is less than 0.001 of the intensity at sea level. A separate group of very hard rays is found of which the rays hardly decrease in number and in ionization between 120 meters ( 230 meters water equivalent) and 143 meters (328 meters water equivalent). The Hoffmann bursts could be recorded at various depths. The decrease in number and intensity was found between sea level and 238 meters water equivalent. The decrease in the magnitude of the bursts shows that the burstproducing rays possess a specific ionization which is about 100 times the ionization of high energy electrons. The burst-producing rays may therefore be neutrons. Bursts and showers are essentially different.Authors' abstract.

3767. DeGolyer, E., Future of petroleum exploration in the United States: Oil Weekly, vol. 35, no. 3, pp. 16-19, Houston, Tex., 1937.

Maintaining reserves of oil necessary for the country can be accomplished only by increasing the effectiveness of prospecting. The author believes that the future of petroleum exploration lies in the organization of separate departments, developing and refining its equipment and technique. The exploration department of the future should be organized to include geologic work; subsurface and surface stra- 
tigraphy; paleontology; geophysics; scouting, engineering, and land leasing; and the drilling of exploratory wells. Three definite and outstanding advantages should result from such a form of organization-(1), development of special equipment and technique for the drilling of exploratory or wildcat wells; (2) development of cost accounting and statistical control; (3) the focusing of attention on exploratory effort and the fixing of responsibility for the degree of success should advance materially the development and application of the technique of prospecting. $-W$. $A$.

376S. Elyy, J. B., Geophysics-its application to petroleum prospecting: Petroleum Engineer, vol. 8, no. 5, pp. 113-135, Dallas, Tex., 1937.

Facts concerning the origin and use of geophysics in the exploration for: the earth's minerals, especially for oil, are presented from the point of view of a geologist interested in geophysics. The application of the torsion balance, gravitimeter, seismograph, and magnetometer in geophysical prospecting is discussed on the basis of typical surveys published in a series of articles. Diagrams and photographs are given.-W. $A$.

3769. Fabiani, Ramiro, Raffronto preliminare fra caratteristiche geologiche e geofisiche in Sicilia [Preliminary comparison between geologic and geophysical characteristics of Sicily] : Reprint from 16th Internat. Geol. Cong. Rept., 7 pp., 1935.

A sketch of the geology of Sicily is given. After geologic examinations a new regional geophysical survey'was undertaken between 1929 and 1931 , as a basis for further detailed explorations with practical aims. With the help of 120 new gravity stations and 670 magnetic stations maps showing anomalies of gravity and of terrestrial magnetism have been drawn. The existence of a large area of negative anomalies of gravity in central-southern Sicily (in the regions of Caltanissetta and Agrigento) was confirmed, and the area was much better defined. The greatest development of the gypsum and sulphur formations is in this area, where great masses of salt are found. At the northern and western borders of this area there are oil seepages, but the most conspicuous manifestations of hydrocarbons are in the zone of highly positive gravity anomalies of the Ragusano. The region of the greatest positive anomalies of gravity is in the Iblei Mountains, where igneous rocks are relatively abundant and where there are also wide areas with high positive anomalies of magnetism. The high positive gravity anomalies in the region of Ragusa and Syracuse therefore lead to the assumption that there are also great masses of volcanic rock under the Miocene limestone of that region. In some parts of eastern Sicily the hydrocarbons are found in the volcanic rocks. These obserrations can therefore help in the search for oil and other.hydrocarbons. Other inceresting features of gravity and terrestrial magnetism were foind in western Sicily, where there must also be, at depth, numerous masses of igneous rock, indicated at the surface only by rare dikes and very small masses.-Author's abstract.

3770. Fleming, J. A., Annual report of. the director of the Department of Terrestrial Magnetism: Carnegie Inst. Washington Year Book 35, for 1935-36, pp. 231-280, reprint issued Dec. 11, 1936.

A. summary of the work of the Department is given concerning investigations of the fundamental constituents of matter and their 
interactions for the solution of the problems of terrestrial magnetism and terrestrial electricity, as well as in obtaining more information about the phenomena themselves and about other geophysical features upon which these phenomena depend.

In the 'investigations dealing with the fundamental properties of matter a new physical force of universal importance was directly observed and measured for the first time. This force, like gravitation, is a basic characteristic of all material things. It is the attractive force between the primary constituents of matter which binds the protons and neutrons together to form the atomic nuclei of all the chemical elements. This is a most outstanding result, realized from the nuclear-physics program which was begun at the Department in 1926 with the objective of disclosing fundamental facts bearing on the intrinsic nature of magnetism, and which is considered important in arriving at an understanding of the magnetic and electric fields of the earth.

Investigations in mathematical statistics connected with the study of terrestrial magnetism and electricity were continued, with particular attention to deriving simplified methocis adequate to develop correctly the morphology of time curves describing cyclic and periodic: phenomena, as compared with random fluctuations.

Researches are being. made in many other fields of geophysics where the methods of statistical analysis are of first importance. A list of the published contributions of investigators and research associates of the Department during July 1, 1935, to June 30, 1936, is added.-Condensed from anthor's summary by W. A.

3771. Mills, Brad, Geophysical advancements keep pace with stringent Gulf coast requirements: Oil Weekly, vol. 84, no. 6, pp. 35-42, 1937.

Most of the geophysical work now under way along the Gulf coast is being done with the torsion balance and reflection seismograph. The work involves the following types of activity: (1) Oil prospects; (2) reconnaissance; (3) second- and third-rate prospects; (4) faults; (5) twin domes; (6) domes in the immediate vicinity of old prospects. The monthly cost of running the 72 reflection-seismograph crews now active in the Texas-Louisiana Gulf coast region is almost $\$ 650,000$, and the monthly cost of running 34 active torsion-balance crews approximates $\$ 135,000$.

The following recent improvements in both equipment and operative technique are mentioned: (1) Lighter and more efficient geophysical equipment has been developed. (2) The detectors are more sensitive. (3) Operators are using sometimes eight detectors instead of six; it is even not unusual to find any number between 5 and 12 in use to meet the various requirements and conditions. (4) A recent development is also a new amphibian "swamp buggy." This vehicle is gasoline-driven, has a four-wheel drive connection, and performs equally well in water or on land. Giant pneumatic tires are used. (5) Another improvement is a receiving set that can be carried by hand into the swamps. This type of reflection seismograph weighs less than 100 pounds, with no loss in effectiveness. (6) Improvement in receiving: equipment has eliminated the necessity for discharging large quantities of dynamite to obtain satisfactory reflections. The amount varies from a very few ounces to 100 pounds. (7) Reflections are now obtained from any desired depth. 
The important part played by the geologist in all phases of geophysical work is described, and the conclusion is drawn that geophysical work during 1937 probably will be as extensive as during the last 2 years.-W. $A$.

3772. Weatherby, B. B., The organization of an effective exploration department: Geophysics, vol. 1, no. 2, pp. 179-188, 1936.

Reviews the functions of a land, lease, and exploration department in a large oil company and describes in detail the integral parts. Criteria are furnished for the background of men suitable for the various positions, and a detailed organization chart is submitted which. also shows the flow of information obtained by the various field methods. Much stress is placed upon the need for detailed, routine reports. The part played by contracting geophysical-exploration companies is also described, and the extent of the service which they should render is shown.--World Petroleum, vol. 8, no. 1, p. 49, 1937.

3773. Ziele und Arbeitsverfahren der geophysikalischen Erdölsuche an der Golfküste von Texas und Louisiana [Purposes and methods of geophysical prospecting for oil on the Gulf coast of Texas and Louisiana] [editorial]: Oel und Kohle, vol. 13, no. 9, pp. 207-208, Berlin, 1937.

The main problems of geophysical work in Texas and Louisiana during the last 4 years are summarized as follows: (1) Prospecting for new oil fields and resurveying old ones; (2) regional investigations for finding deeper prospective structures; (3) revision of prospects which were considered previously unimportant; (4) detection of faults; and (5) detection of "twin" domes in the neighborhood of old known prospects. The main work in 1936 was done by torsion balance ( 34 crews) and reflection seismograph (72 crews). Depths of 3,500 and even 4,500 meters were attained. Improvements in technique of the work are mentioned.-W. $A$.

\section{GEOLOGY}

3774. Gesti, Josef, Schichtungsvorgang in einem inhomogenen schweren Weltkörper hoher Temperatur [Stratification process in a heterogeneous heavy celestial body of high temperature]: Gerlands Beitr. Geophysik, vol. 49, no. 1/2, pp. 26-65, Leipzig, 1937.

The theory of the stratification of the interior of the earth developed in this article rejects the conception of the accumulation of matter by drops sinking gradually by gravity to the center of the earth. According to this theory gravitational stratification proceeds by two or more steps: matter first accumulates in the form of spherical drops in the peripheral part of the earth (in the zone of liberation) and then settles down at the central part in the form of enormous masses deposited eccentrically. An indirect way is chosen to prove this theory; the conclusions on the process in the interior of the earth are drawn from the conditions found in the earth's crust. The conclusions agree well with the observations.

The forces by which the faulting of the earth's surface is made possible are indicated by this theory, and it explains the formation of geosynclines. The theory offers probable explanations of pole movements, strong earth-current movements, changes in climate, and, 
especially, the periodicity of mass deformations at depth by which the reasons for the repeated diastrophic processes-that is, the establishment of geologic epochs-may be made clear.-Author's abstract, translated by W. A.

3775. Thom, W. T., Jr., Position, extent, and structural make-up of Appalachia : Geol. Soc. America Bull., vol. 48, no. 3, pp. 315-322, 1937.

Considering the form and relative positions of the areas of positive anomalies and the geology of the region, it seems clear that the surface gravitational variations are relatively independent of the topographic configuration of the basement surface and are indicative of the presence of local and abnormally heavy rock bodies embedded just below the surface of the basement complex. Such heavy masses would appear to lie nearest the surface of the earth at Hoboken, and at progressively greater depths as the eastern zone of "highs" is traced southwestward. It may further be suggested that these heavy bodies are intrusive masses. In order to determine what these intrusive masses may be, how deep they lie, and what geologic significance they have, it would be desirable to collect data as follows, using the method of multiple approach.

First, intensive seismic traverses should be made in various directions across the gravitational "highs" near Washington and Philadelphia, and across the "trough" to the northwest, using quarry blasts as the main source of energy. Second, additional pendulum observations should be made at critical points throughout the region, in order to obtain better control for the gravitational "picture." These primary stations should be connected by second-order observations intended to reveal and record both the variation in direction of the local horizontal components of gravity and the local variations of the magnitude of the vertical component. Third, a study should be made, and extended as may be necessary, of the existing information concerning variations in the local terrestrial magnetic fields and in the earth's electrical properties, along selected profiles from the Allegheny Front to the Atlantic coast.

By comparing the results thus yielded by two or more geophysical methods in any area where the surface structure and composition of the crustal rocks are geologically known, accurate geologic interpretations of the geophysical data should be possible, both downward and laterally. Moreover, by thus using the emergent western portion of Appalachia as a "calibration area", it would certainly be possible to learn much that is of prime importance in regard to the extent, the physical make-up, and the tectonic history and relationships of this old land mass, which once stood relatively high above sea level and since has been faulted, warped downward, and extensively submerged.-From author's conclusions.

\section{NEW BOOKS}

3776. Manual of geophysical prospecting with magnetometer, $129 \mathrm{pp}$; 53 ills., Houston, Tex., American Askania Corporation, 1936. Price $\$ 1.50$.

The purpose of the manual is (1) to familiarize the reader with the fundamental principles that underlie the operation of the Schmidt magnetometer; (2) to describe the physical features of the Schmidt magnetometer; $(3)$ to discuss various factors that influence observa- 
tions; (4) to indicate corrections to be applied to field data; (5) to enumerate the precautions to be observed in handling and using the instrument; (6) to describe field procedure in operating the instrument; (7) to cover possible sources of difficulty in operation and their remedy; (8) to indicate methods of determining instrument constants ; (9) to describe various methods of presenting magnetometer results; and $(10)$ to outline certain fundamental ideas that underlie the interpretation of magnetic data.-W. $A$.

3777. Seismology: Carnegie Inst. Washington Year Book 35, for 1935-36, pp. 368-379, reprint issued Dec. 11, 1936.

This is a report of the Advisory Committee in seismology. It contains the following articles: (1) Collaboration with the U. S. Coast and Geodetic Survey (information furnished by William Bowie); (2) The seismological laboratory (extract from the annual report of H. O. Wood) ; and (3) Earthquake activity, by C. F. Richter and R: E. Rogers. $-W . A$.

3778. Geophysics, a journal of general and applied geophysics, vol. 1, no. 2, pp. 179-297, Houston, Tex., Soc. Petroleum Geophysicists, June 1936. Price $\$ 3$.

Contents: (1) The organization of an effective exploration department, by B. B. Weatherby, pp. 179-188; (2) A proposed geophysical program of exploration for Nebraska and the Dakotas, by J. H. Wilson, pp. 189-195; (3) Visual presentation of elastic wave patterns under various structural conditions, by F. Rieber, pp. 196-218; (4) . Relation between firing current and performance in seismograph caps, by $L$. A. Burrows, pp. 219-227; (5) Explosives for seismic prospecting, by N. G. Johnson and G. H. Smith, pp. 22S-238; (6) Significance of some fundamental properties of explosives, with special reference to geophysical prospecting, by H. E. Nash and J. M. Martin, pp. 239-251; (7) The amplitudes of waves to be expected in seismic prospecting, by B. Gutenberg, pp: 252-256; (8) Note on reflections from steeply dipping beds, by C. A. Heiland, pp. 257-271; (9) Electric earth transients in geophysical prospecting, by L. Statham, pp. 271-277. The book contains also two reviews of new publications (Geophysical prospecting, by Lancaster Jones, published by the Physical Society, London, 1936, reviewed by M. M. Slotnick; and Flash spotters and sound rangers, how they lived, worked, and fought in the Great War, compiled by John R. Jones and published by George Allen \& Unwin, Ltd., Museum Street, London, England, price $\$ 2.50$, reviewed by E. E. Rosaire) ; list of publications of the Society of Petroleum Geophysicists, with dates of publication and nature of contents; and a list with abstracts of 35 papers presented at the technical program of the annual meeting, Tulsa, Okla., March 19-21, 1936.-W. A.

3779. Geophysics, a journal of general and applied geophysics, vol. 1, no. 3, pp. 299-385, Houston, Tex., Soc. Petroleum Geophysicists, October 1936. Price $\$ 3$.

Contents: (1) On seismic computations, with applications, II, by M. M. Slotnick, pp. 299-305; (2) The growth of company-owned operations in Gulf coast geophysical prospecting since July 1930 , by E. E. Rosaire and K. Ransone, pp. 306-312 ; (3) Effect of development time and developer temperature on the production of photographic seismic 
records, by F. A. Tompkins, pp. 313-318; (4) The amplitude and character of refraction waves, by $A$. Wolf, pp. $319-326$; (5) The seismic electric effect, by R. R. Thompson, pp. $327-335 ;(6)$ A simplified circuit of the seismic electric method and its steady-state solution, by M. M. Slotnick, pp. 336-339; (7) True ground motion from mechanical seismograph records, by A. B. Bryan, pp. 340-346; (8) An experimental study of the elastic properties of rocks, by J. M. Ide, pp. $347-352$; (9) Interstitial water saturation in the pore space of oil reservoirs, by J. A. Lewis and W. L. Horner, pp. 353-364; (10) Some aspects of multiple recording in seismic prospecting, by $\mathbf{P}$. W. Klipsch, pp. 365-377.

Reviews of the following five articles are given: (1) Prospeção geophysica em São Paulo, by Irnack Carvalho do Amaral and Henrique Capper Alves de Sousa: Dept. Mineral Production, Republic of Brazil, Bull. 10, Rio de Janeiro, 1936 (in Portuguese), reviewed by J. H. Wilson; (2) Deformation of rocks under high confining pressures, I, Experiments at room temperature, by D. T. Griggs: Jour. Geology, vol. 44, no. 5, pp. 541-577, 1936, reviewed by M. Mott-Smith; (3) Shearing phenomena at high pressures of possible importance for geology, by P. W. Bridgman: Jour. Geology, vol. 54, pp. 653-669, 1936, reviewed by C. M. Boos; (4) Magnetic investigations in southwest Alabama: Alabama Univ. Bull. 43, June 1936, reviewed by J. L. Adler; (5) Some magnetometric and gravimetric surveys in the Transvaal, by $O$. Weiss, D. T. Simpson, and G. L. Paver: Union of South Africa, Dept. Mines, Geol. ser., Bull. 7, 1936, reviewed by D. C. Barton.-W. A.

3780. Gulf coast oil fields ; edited by D. C. Barton and George Sawtelle, 1,100 pp.r 292 figs., 19 halftone plates, Tulsa, Okla., Am. Assoc. Petroleum Geolo. gists, 1936. Price $\$ 4$.

Consists of 44 papers contributed by 52 authors. There are 14 general and theoretical papers dealing largely with the mechanics of saltdome formation, structural features of salt domes, relations of geophysics to salt-dome structure, and related topics.-W. $A$.

3781. Innes J. R., Flash spotters and sound rangers-how they lived, worked and fought in the Great War, 308 pp., London, England, George Allen \& Unwin, Ltd., Museum Street, 1936. Price $\$ 2.50$.

This book is the result of the collaboration of many persons, named and unnamed. A chapter of special interest is contributed by Prof. W. L. Bragg, O. B. E., M. C., F. R. S., who, with the aid of photographs and diagrams, gives a simple explanation of the "mysteries" of sound ranging. The rank and file, who are allowed to speak for themselves, make several notable contributions, and the illustrations are from sketches made by the men in their spare time at the front. Captain Innes, who was the adjutant of the 1st Field Survey Battalion, R. E., and who received a mention in dispatches, has woven the threads skillfully to provide a pattern that is refreshingly informal. ** * The book is a serious contribution to the history of the war.-Publisher's abstract.

Primarily of historical interest, since the present applications of the seismograph in geophysical prospecting received an important stimulus from the sound-ranging methods developed during the World War. Recommended as light reading for those reflection seismograph operators who did not acquire refraction experience.-E. E. Rosaire. 
3782. National Research Council of Japan, Geophysical observations during the total solar eclipse June 19, 1936: Japanese Jour. Astronomy and Geophysics, vol. 14, no. 2, pp. 87-279, Tokyo, 1937.

Contains the following articles: (1) Observations of terrestrial magnetism and earth current at Tomarigisi, Wakkanai, Iwamizawa, and Hirosaki during the total solar eclipse of June 19, 1936; by M. Hasegawa, pp. $87-102$; (2) Observations of the magnetic elements and earth potential during the total solar eclipse of June 19, 1936, by S. Ono, pp. 103148 ; (3) Report of the geophysical party of the solar eclipse expedition of Tohoku Imperial University on observations in Karahuto and Hokkaido, by S. T. Nakamura, pp. 149-156; (4) On variation in earth current during the total solar eclipse of June 19, 1936, by Y. Kato, pp. 157162 ; (5) Magnetic observations of the Hydrographic Department, Imperial Japanese Navy, by S. Kuwahara, pp. 163-180; (6) Results of magnetic observations during the solar eclipse of June 19, 1936, in Manchuria, by S. Hayami, H. Hagasinaka, and K. Senda, pp. 181-212; (7). On the observations of terrestrial magnetism, atmospheric electricity, and earth current made during the total eclipse of the sun, June 19, 1936, by S. Imamiti, H. Hatakeyama, and T. Yosimatu, pp. 213-218; (8) On the effect of the eclipse on radio transmission observed in Japan, by T. Kazii, pp. 219-223; (9) Ionospheric measurements during the total eclipse of June 19, 1936, made by the Electrotechnical Laboratory, Ministry of Communications, by K. Maeda, pp. 224-225 ; (10) Ionospheric studies during the solar eclipse of June 19, 1936, by T. Minohara and Y. Ito, pp. 225-232; (11) Observations of electric waves in Manchuria during the total solar eclipse of June 19,1936 , by T. Nakamura, pp. 233254 ; (12) Measurements of the fleld intensity and of the ionosphere in the solar eclipse of June 19, 1936, by M. Iwatake, T. Furuno, Y. Takeda, and R. Terae, pp. 255-263; (13) Spectrographic observation of the amount of atmospheric ozone at the total solar eclipse of June 19, 1936. by Y. Kawabata, pp. 264-265; (14) Measurements of cosmic rays during the solar eclipse of June 19, 1936, by Y. Nishina, Ch. Ishii, Y. Asano, and Y. Sekido, pp. 265-276; (15) Optical investigations at Memanbetu during the total eclipse of the sun, June 19, 1936, by T. Kitaoka, pp. 277-27s; (16) Longitude and latitude of Okusibe, Hokkaido, by Y. Tukamoto, p. $279 .-W . A$.

\section{PATENTS}

3783. Subsurface exploration; Bills, Robert N., Tulsa, Okla., assignor to Geophysical Research Corporation, New York, N. Y., a corporation of New Jersey; U. S. patent 2074161, issued March 16, 1937.

This invention relates to the method of receiving artificial seismic waves transmitted through earth having a surface layer of soft material which comprises sinking a rod through the soft surface layer into the hard material below, mounting a wave detector on the upper end of said rod, and receiving by said detector the waves transmitted thereto from the hard material through said rod. Claims allowed, 1.

3784. Seismograph, Blau, Ludwig W., and Statham, Louis, Houston, Tex., assignors to Standard Oil Development Co., a corporation of Delaware; U. S. patent 2074043, issued March 16, 1937.

In a seismograph, a frame, a coil wound on a rigid iron core, the ends of the core protruding from the coil in a horizontal direction, 
means immovably securing the coil to the frame, and a movable system, including magnets of large inertia, means yieldably suspending: the magnets from the frame for movement in a vertical direction with the poles of the magnets disposed on opposite sides of and spaced from the ends of the core, whereby the magnets are maintained substantially stationary when the frame is subjected to seismic vibrations: and motion of the core relative to the magnets induces electromotive force across the coil. Claims allowed, 4 .

3785. Method of and apparatus for electrically exploring earth formations; Huber, Frederick W., Riverside, Calif., assignor to Geoanalyzer Corporation, Los Angeles, Calif., a corporation of California ; U. S. patent: 2072950, issued March 9, 1937.

This invention relates to the method of determining the nature of the natural fluid contained in a porous formation traversed by a bore hole containing a conductive fluid, which comprises measuring and comparing variations in the electrical resistivity of the formation. parallel and close to the bore hole where the formation is permeated with the conductive fluid of the bore hole and parallel to but spaced: from the bore hole a distance greater than the distance of penetration of the bore-hole fluid from the bore hole into the formation. Claims allowed, 6.

3786. Method of electrically exploring bore holes; McDermott, Eugene, Dallas, Tex. ; U. S. patent 2070912, issued February 16, 1937.

This invention relates to the method of electrically exploring bore holes which consists in elevating the hole-boring tool a predetermined distance above the bottom of the bore hole, in lowering an:electrodethrough the rotary drill stem and through a hole in the drill bit of the hole-boring mechanism, in suspending said electrode in the bore hole operatively below said drill bit and insulating the same therefrom, in electrically connecting said electrode with a battery and suitable indicating instruments and the surface of the ground, and in observing: the change of voltage and current by means of said indicating instruments as the position of the electrode is changed in the hole. Claims allowed, 4.

3787. Torsion balance; Roux, Erwin; Berlin-Friedenau, and Imhof, Hermann, Berlin-Steglitz, assignors to Askania-Werke Aktiengesellschaft, BerlinFriedenau, Germany, a corporation of Germany ; U. S. patent 2075625, issued March 30, 1937.

This invention relates to a torsion-balance apparatus comprising, in combination, a support housing having viewing means at its upper portion and transparent portions spaced about its side walls; means on the exterior of said housing adjacent to each of said transparent portions for detachably mounting a torsion balance thereon as a unit; and means within said housing for receiving beams of light from each of said units reflected through said transparent portions and projecting said beams upon said viewing means. Claims allowed, 8.

3788. Apparatus for well surveying; Straatman, A. G. H., The Hague, Netherlands, assignor to Shell Development Co., San Francisco, Calif., a corporation of Delaware; U. S. patent 2076211, issued April 6, 1937.

This invention relates to an apparatus for surveying subsurface strata traversed by a bore hole, comprising a metallic element of rela- 
tively large heat capacity capable of being lowered into a bore hole and of following the general temperature'trend of the bore-hole fluid, means associated with said element and responsive to a difference in temperature between said element and the well liquid surrounding said element, and means cooperating with said temperature-responsive means adapted to register said temperature difference. Claims allowed, 5.

3789. Device for determining the existence or the direction 'of a magnetic field; Caretta, Ettore; Corso Raffaello 19; Turin, Itảy'; British patent 451850 , issued August 10, 1936.

This invention relates to an arrangement including indicating means for determining the presence or the direction of a magnetic fleld by measuring the induced electric current in one or more coils wound on a magnetic core, by the variations of said field, characterized in that there is produced in a portion of the magnetic circuit a periodic varying flux and consequently of reluctance, by means of auxiliary coils carried on said core, in which coils a variable electric current is passed under conditions such that the said current exerts no influence on the indicating means. Claims allowed, 6.

3790. Improvements in or relating to torsion balances; Elwerath, Gewerkschaft, and Reeh, Erich, both of Ebelingstrasse 11, Hannover, Germany ; British patent 457027, issued November 19, 1936.

According to this invention the suspension of system is arranged in a metallic housing having a thickness of wall about as great as or greater than the diameter of the oscillation space; the housing is formed of sereral metallic tubes which are a sliding fit in one another; the housing is made of aluminum. Claims allowed, 4.

3791. Improvements in methods of measuring the magnitude of the force of gravity ; Lindblad, A. R., Västra Trädgårdsgatan, Stockholm, Sweden; British patent 451817, issued August 12, 1936.

This invention relates to an improved method of measuring the force of gravity or variations in the same, with the use of a movable body, the weight of which has been counterbalanced or biased out by means of a spring device, an electric or magnetic field, or in other manner. A characteristic feature of the invention consists therein, that this movable body, in its end position, or in other predetermined positions during its movements, closes or opens an electrical contact, for the purpose of indicating, by this means, when the body is at these positions. Claims allowed, 4.

3792. Improved apparatus for measuring the magnitude of the force of gravity; Lindblad, A. R., 17 Västra Trädgårdsgatan, Stockholm, Sweden ; British patent 455398 , issued October $20,1936$.

This invention relates to an apparatus for measuring the force of gravity or variations in the same-for instance, for the purpose of detecting and determining the position of metalliferous or other mineral deposits-comprising a movable body forming a permanent part of the apparatus and the weight of which has been counterbalanced by means of a spring device, an electromagnetic field, or other suitable manner, the said body, as it moves, directly influencing an electric or -magnetic field in such a manner that the position of the body may be accurately determined by observing the variations in this field. Claims allowed, 5. 
3793. Improvements in methods of measuring the force of gravity; Lindblad, A. R., of 17 Västra Trädgårdsgatan, Stockholm, Sweden; British patent 455405, issued October 20, 1936.

This invention consists of measuring the force of gravity or variations in the same, with the aid of a movable body, the weight of which has been - counterbalanced "or biased wout by means of a spring device or in other manner, a method in which said movable body is adapted, during its movements, to influence two separate electric or magnetic fields and is returned to its neutral position by one of the two electric or magnetic fields, the strength of which is read off by suitable instruments, such as a voltmeter or the like, which strength serves as a measure of the magnitude of the force of gravity. Claims allowed, 3.

3794. A method and apparatus for detecting water intrusion in bore holes; Naamlooze Vennootschap de Bataafsche Petroleum Maatschappij, 30 Carel van Bylandtlaan, The Hague, Holland: British patent 452076, issued August 17, 1936.

This invention relates to a method of locating water-bearing strata in a well, comprising producing a uniform opaqueness in the liquid in said well, lowering a photoelectric opaqueness indicator into said well, moving said indicator through said liquid, and recording variations in the opaqueness by said indicator by said movement. Claims allowed, 11.

3795. Procédé et dispositifs pour déterminer l'orientation et éventuellement la valeur du pendage des terrains recoupés par un sondage [Method and apparatus for determining the direction and eventually the value of the dip in the ground penetrated by boring]; Société de prospection électrique (Procédés Schlumberger) of France (Seine) ; French patent 804111, issued October 16, 1936.

This invention relates to the method for determining the direction and the value of the dip in the ground penetrated by boring; it consists of measuring the differences of spontaneous potentials existing in the hole at the contacts of porous layers with nonporous layers, the measurements being made not along the axis of the hole but close to the walls of the hole. From the data obtained at two opposite points of the wall the direction of the dip may be deduced. Claims allowed, 5 .

3796. Dispositif pour déterminer l'orientation et la valeur du pendage des couches traversées par un sondage [Apparatus for determining the direction and the value of the dip of layers penetrated by boring]; Société de prospection électrique (Procédés Schlumberger) of France (Seine) ; French patent 805691, issued November 26, 1936.

This invention relates to an apparatus for determining the direction and the value of the dip of the layers penetrated by boring. The apparatus consists of a combination of a device designed for taking cores in any direction in the wall of the hole and a device by which the direction and the inclination of the first device at the moment of taking the core may be determined by a photographic picture of the position of the magnetic needle and of the bubble of the water level. Claims allowed, 2. 
3797. Perfectionnement aux dispositifs électriques pour la reconnaissance des terrains et en particulier des couches pétrolifères et aquifères traversées par un sondage [Improvement of electrical apparatus for investigating the ground and especially of petroleum-bearing and water-bearing layers penetrated by boring]; Société de prospection électrique (Procédés Schlumberger) of France (Seine); French patent 809152, issued February 25, 1937.

This invention relates to the improvement of apparatus for measuring the electrical resistance of layers penetrated by boring. The apparatus has one or two electrodes carrying the current; these electrodes are lowered into the mud of the hole. One or two other electrodes serving for measuring the differences of the potential produced by this current are also lowered into the well. The improvement consists essentially in the fact that one of the electrodes carrying the current is united with one of the measuring electrodes, the circuits of the sending current and of measurement remaining at the same time separated. This united electrode has preferably a cylindrical form with a diameter slightly smaller than that of the hole. The electrode is provided with ballast serving for lowering it into the bole. Claim allowed, 1. 



\section{INDEX}

The figure in parentheses refers to the class in which the entry stands; see list in table of contents

\begin{abstract}
American Askania Corporation (8) --American Association of Petroleum Geologists (9)

Angenheister, G. (3)

Antonov, P. L: (7)

Arnold, G. (4)

Askania-Werke, Aktiengesellschaft (10)
\end{abstract}

Barbey, O. (4)

Barrow, W. L. (4)

Bills, R. N. (10)

Blau, L. W. (7) (10):

Bols, Charles (3)

Born, K: E. (2)

Bullard, E. C. (1)

Buwalda, J. P. (3)

Caloi, P. (3)

Caretta, Ettore (10)

Carnegie Instltution of Washington (9)

Carson, J. R. (4)

Clay; J. (7)

Crạry, A. P. (3)

Day, L. J. L. (7)

DeGolyer, E. (7)

Dostovalov, B. N. (4)

Eble, Louis (7)

Eby, J. B. (7)

Einaudi, Renato (3)

Elwerath Gewerkschaft (10)

Evans, R. D. (5)

Evsejev, S. V. (1)

Wwing, Maurice (3)

Fabiani, Ramiro (7)

Faltas, Fayek (3)

Fedukovich, V. (4)

Fleming, J. A. (7)

Fritsch, Volker (4)

(3)

Abstract

8776

3780

3689

3764

3735

3787

3736

3754

3783

3765

3784

3700

3698

3661

3706

3701

3789

3777

3755

3766

3703

3766

3767

3737

3679

3768

3702

$\$ 790$

3758

3657

3703

3769

3704

3739

3770

0, 3741

Geoanalyser Corporation (10)

Gesti, Josef (8)

Gibsone, John (2)

Glennie, E. A. (1) -

Golovtzyn, V. N. (4)

Grenet, G. (3)

Gunn, R. (1)

Gutenberg, B. (3)
3785

3774

3680

3658

3742

3705

3659

3706
Hameister, Ernst (2) Hasegawa, Mankiti (2) Hazard, D. L. (2) Heiland, C. A. (3)

Heinrich (3)

Holweck, F. (1)

Hooft, C. G. (7)

Horsfleld, W. (1) _......... 3661

Horvath, Sepp (4)

Huber, F. W. (10)

Hughson, W. G. (1) _..._._._. 3668

Hummel, J. N. (4) _..._... 3744

Iida, Kumizl (3)

Imhof, Hermann (10)

Innes, J. R. (9)

Ishimoto, Mishio (3) 3709

Jakosky; J. J. (4)

Jeffreys, Harold (1) _..._..._._. 3662

- (3) --_-_- 3710

Kanal, Kiyoshi (3) _._._._._.-. 3721 , $3722,3723,3725,3726$

Kawasum1, Hirosi (3) _._.....- 3711,3712

Ǩye, M. K. (3)

Kinosita, Zyun'iti (3)

Kirillov, F. A. (3) _.

Kraskovski, S. A. (6) _..._. 3762,3763

Kurbatov, L. M. (5)

Lagrula, J. (1) _-

Lambert, W. D. (1) _._._....... 3664

Lane, A. C. (5)

Lejay, P. (1)

Lettau, Helnz (1)

Leushin, P. J. (1)

Lindblad, A. R. (10) _._._. 3791, 3792, 3793

Liwy, H. (4) - 3746

Lynch, J. J. (3) _. 3715

Martin, H. (3) (-

McDermott, Eugene (3)

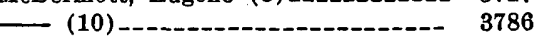

McFarland, W. N. (2) _._._._. 3684

Mead, S. P. (4)

Mikhailov, I. G. (4) _._._. $3747,3748,3749$

Miller, A. H. (1) _._._. 3668

Mills, Brad (7)

Miyabe, Naomi (1) _._._-_._-_ 3609, 3670

Molin, Kurt (2) _.

Mouzon, J. C. (5) _-

Munsey, D. F. (1) 
Naamlooze Vennootschap de Bataafsche Petroleum Maatschappij (10) _

National Research Council of Japan (9)

Norton, K. A. (4)

Oel und Kohle (editorial) (7)

Orkisz, Henryk (2)

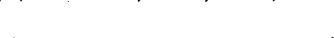

Petroleum Engineer (editorial) (4) --

Puchkov, S. V. (3)

Pylaev, A. M. (4)

Ramspeck, A. (3)

Rayner, J. M. (2)

Reeh, Erich (10)

Reich, H. (3)

Renner, J. (1)

Rieber, Frank (3)

Roman, Irwin (2)

Roux, Erwin (10)

Rülke, O. (4)

Rutherford, H. M. (3)

(3)

Schafer, Sidney (2)

Schelkunoff, S. A. (4)

Schmidt, K. H. (1)

Schwinner, Robert (1)

Sermon, T. C. (2)

Sezewa, Katsutade (3) $\begin{array}{r}3722,3723,2724,3725,3726 \\ \hline\end{array}$

Shakhnes,' K. A. (4)

Shaw, S. H. (4)

3751

(4)

Shell Development Co. (10)
Shnirman, G. L. (3)

Abstract Siemens, Günter (2)

$3727,3728,3729$

Skriabin, V. I. (3)

Société de prospection électrique (10) Society of Petroleum Geophysicists (9)

3778,3779

Sckoloff, P. T. (3) _... 3730

Soloviev, A. V. (4)

Soské, J. L. (2)

Southworth, G. C. (4) _-_ 3757

Stagg, J. M. (2)

Standard Oil Development Co. (10) - 3784

Statham, Louis (10) - -

Stoneley, R. (3) _._.

Straatman, A. G. H. (10) _... 3788

Stubbe, G. (1)

Swick, C. H. (1) _... 3675

Szecsödy, C. H. (1)__-_._- 3676

Thellier, Emile (2) _-_-_-_-_ 3695, 3696

Thom, W. T., Jr. (8)

Thyssen, Stephen von (1)

Uhrig, L. F. (2) 3697

Ulrich, F. P. (3)

Urren, L. C. (3)

Van Bemmelen, R. W. (1)

Weatherby, B. B. (7)

Wiersma, J. T. (7)

Wilson, C. H. (4)

Wilson, C. W., Jr., (2) _... 3698

IIII 